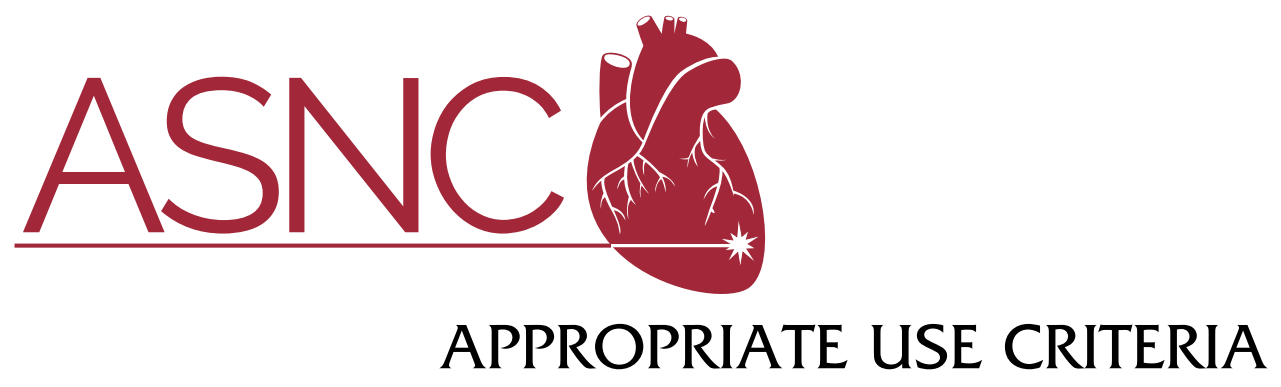

\title{
ACC/AATS/AHA/ASE/ASNC/HRS/SCAI/SCCT/SCMR/STS 2017 APPROPRIATE USE CRITERIA FOR MULTIMODALITY IMAGING IN VALVULAR HEART DISEASE
}

\begin{abstract}
A Report of the American College of Cardiology Appropriate Use Criteria Task Force, American Association for Thoracic Surgery, American Heart Association, American Society of Echocardiography, American Society of Nuclear Cardiology, Heart Rhythm Society, Society for Cardiovascular Angiography and Interventions, Society of Cardiovascular Computed Tomography, Society for Cardiovascular Magnetic Resonance, and Society of Thoracic Surgeons
\end{abstract}

This document is 1 of 2 companion appropriate use criteria (AUC) documents developed by the American College of Cardiology, American Association for Thoracic Surgery, American Heart Association, American Society of Echocardiography, American Society of Nuclear Cardiology, Heart Rhythm Society, Society for Cardiovascular Angiography and Interventions, Society of Cardiovascular Computed Tomography, Society for Cardiovascular Magnetic Resonance, and Society of Thoracic Surgeons. This document addresses the evaluation and use of multimodality imaging in the diagnosis and management of valvular heart disease, whereas the second, companion document addresses this topic with regard to structural heart disease. Although there is clinical overlap, the documents addressing valvular and structural heart disease are published separately, albeit with a common structure. The goal of the companion AUC documents is to provide a comprehensive resource for multimodality imaging in the context of valvular and structural heart disease, encompassing multiple imaging modalities.

Electronic supplementary material The online version of this article (doi:10.1007/s12350-017-1070-1) contains supplementary mate rial, which is available to authorized users.

This document was approved by the American College of Cardiology Clinical Policy Approval Committee in June 2017.

The American College of Cardiology requests that this document be cited as follows: Doherty JU, Kort S, Mehran R, Schoenhagen P, Soman P. ACC/ AATS/AHA/ASE/ASNC/HRS/SCAI/SCCT/SCMR/STS 2017 appropriate use criteria for multimodality imaging in valvular heart disease: a report of the American College of Cardiology Appropriate Use Criteria Task Force, American Association for Thoracic Surgery, American Heart Association, American Society of Echocardiography, American Society of Nuclear Cardiology, Heart Rhythm Society, Society for Cardiovascular Angiography and Interventions, Society of Cardiovascular Computed Tomography, Society for Cardiovascular Magnetic Resonance, and Society of Thoracic Surgeons. J Am Coll Cardiol 2017;70:1647-72.

This document has been reprinted in the Journal of the American Society of Echocardiography, Journal of Nuclear Cardiology, and the Journal of Thoracic and Cardiovascular Surgery with permission of the American College of Cardiology.

Copies: This document is available on the World Wide Web site of the American College of Cardiology (www.acc.org). For copies of this document, please contact Elsevier Reprint Department, fax (212) 633-3820 or e-mail reprints@elsevier.com.

Permissions: Multiple copies, modification, alteration, enhancement, and/or distribution of this document are not permitted without the express permission of the American College of Cardiology. Requests may be completed online via the Elsevier site (https://www.elsevier.com/about/ourbusiness/policies/copyright/permissions).

J Nucl Cardiol 2017;24:2043-63.

$1071-3581 / \$ 34.00$

Copyright @ 2017 American College of Cardiology Foundation.

doi:10.1007/s12350-017-1070-1. 
Using standardized methodology, the clinical scenarios (indications) were developed by a diverse writing group to represent patient presentations encountered in everyday practice and included common applications and anticipated uses. Where appropriate, the scenarios were developed on the basis of the most current American College of Cardiology/American Heart Association guidelines.

A separate, independent rating panel scored the 92 clinical scenarios in this document on a scale of 1 to 9 . Scores of 7 to 9 indicate that a modality is considered appropriate for the clinical scenario presented. Midrange scores of 4 to 6 indicate that a modality may be appropriate for the clinical scenario, and scores of 1 to 3 indicate that a modality is considered rarely appropriate for the clinical scenario.

The primary objective of the AUC is to provide a framework for the assessment of these scenarios by practices that will improve and standardize physician decision making. AUC publications reflect an ongoing effort by the American College of Cardiology to critically and systematically create, review, and categorize clinical situations where diagnostic tests and procedures are utilized by physicians caring for patients with cardiovascular diseases. The process is based on the current understanding of the technical capabilities of the imaging modalities examined. disease

Key Words: ACC Appropriate Use Criteria $\cdot$ imaging $\cdot$ multimodality $\cdot$ valvular heart

\section{Writing Group Members}

John U. Doherty, MD, FACC, FAHA, Chair*, Smadar Kort, MD, FACC, FASE, FAHA ${ }^{\dagger}$, Roxana Mehran, MD, FACC, MSCAI, FAHA Paul Schoenhagen, MD, FAHA ${ }^{\S}$, Prem Soman, MD, PhD, FACC

* American College of Cardiology Representative. ${ }^{\dagger}$ American Society of Echocardiography Representative. *Society for Cardiovascular Angiography and Interventions Representative. ${ }^{\S}$ Society of Cardiovascular Computed Tomography Representative. "American Society of Nuclear Cardiology Representative

\section{Rating Panel Members}

Greg J. Dehmer, MD, MACC, MSCAI, FACP, FAHA, Moderator*

John U. Doherty, MD, FACC, FAHA, Writing Group Liaison*

Paul Schoenhagen, MD, FAHA, Writing Group Liaison ${ }^{\S}$

Zahid Amin, MD, FSCAI, FAHA

Thomas M. Bashore, MD, FACC*

Andrew Boyle, $M D^{*}$

Dennis A. Calnon, MD, FACC, FASE, MASNC, FSCCT

Blase Carabello, MD, FACC*

Manuel D. Cerqueira, MD, FACC, MASNC*

John Conte, MD"

Milind Desai, MD, FACC*

Daniel Edmundowicz, MD, FACC*

\section{Rating Panel Members continued}

Victor A. Ferrari, MD, FACC

Brian Ghoshhajra MD, MBA ${ }^{\S}$

Praveen Mehrotra, MD, FACC*

Saman Nazarian, MD, PHD**

T. Brett Reece, $M^{\dagger \dagger}$

Balaji Tamarappoo, MD, PHD*

Wendy S. Tzou, MD, FACC, FHRS

John B. Wong, MD

\begin{abstract}
" Society of Thoracic Surgeons Representative. "Society for Cardiovascular Magnetic Resonance Representative. ${ }^{*}$ Heart Rhythm Society Representative. ${ }^{\dagger \dagger}$ American Association for

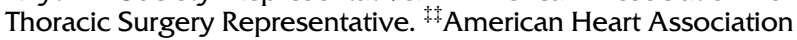
Representative
\end{abstract}

\section{Appropriate Use Criteria Task Force}

John U. Doherty, MD, FACC, FACP, FAHA, Co-Chair

Gregory J. Dehmer, MD, MACC, MSCAI, FACP, FAHA, Co-Chair

Steven R. Bailey, MD, FACC, MSCAI, FAHA

Nicole $M$. Bhave, MD, FACC

Alan S. Brown, MD, FACC $\$ \S$

Stacie L. Daugherty, MD, FACC

Larry S. Dean, MD, FACC, MSCAI

Milind Y. Desai, MBBS, FACC

Claire S. Duvernoy, MD, FACC ${ }^{\S}$

Linda D. Gillam, MD, FACC

Robert C. Hendel, MD, FACC, FAHA ${ }^{\S \S}$

Christopher M. Kramer, MD, FACC, FAHA ${ }^{\|\|}$ 


\section{Appropriate Use Criteria Task Force continued}

Bruce D. Lindsay, MD, FACC $\$ \S$

Warren J. Manning, MD, FACC

Praveen Mehrotra, MD, FACC, FASE

Manesh R. Patel, MD, FACC, FSCAI, FAHA ${ }^{\text {"थ }}$

Ritu Sachdeva, MBBS, FACC

L. Samuel Wann, MD, MACC ${ }^{\S \S}$

David E. Winchester, MD, FACC

Michael J. Wolk, MD, MACC ${ }^{\S \S}$

Joseph M. Allen, MA ${ }^{\S}$

$\S \S$ Former Task Force member; current member during writing effort. "I\|IFormer Task Force co-chair; current co-chair during writing effort. ${ }^{\text {"F }}$ Former Task Force chair; current chair during writing effort

\section{PREFACE}

Valvular and structural heart disease encompass a significant proportion of cardiovascular disease conditions. Initial diagnosis and subsequent follow-up frequently rely on imaging with more than 1 imaging modality. Rapidly evolving less-invasive and transcatheter treatment options have fueled the need for precise preprocedural and intraprocedural anatomic and functional imaging.

The publication of appropriate use criteria (AUC) reflects 1 of several ongoing efforts by the American College of Cardiology (ACC) and its partners to assist clinicians who are caring for patients with cardiovascular diseases and in support of high-quality cardiovascular care. The ACC/American Heart Association clinical practice guidelines provide a foundation for summarizing evidence-based cardiovascular care and, when evidence is lacking, expert consensus opinion that is approved in review by the ACC and American Heart Association. However, in many areas, variability remains in the use of cardiovascular imaging modalities, raising questions of overuse or underuse. The AUC provide a practical standard upon which to assess and better understand variability.

We are grateful to the writing committee for the development of the overall structure of the document and clinical scenarios, and to the rating panel, a professional group with a wide range of skills and insights, for their thoughtful deliberation of the merits of multimodality imaging for various clinical scenarios. A special thanks to Dr. Gregory Dehmer for serving as an expert moderator at our in-person rating panel meeting. We would also like to thank the AUC Task Force members who provided insight and guidance, and the
ACC staff-Leah White and especially María Velásquez-for their skilled support in the generation of this document.

\author{
John U. Doherty, MD, FACC, FAHA, FACP \\ Chair, Multimodality Imaging in Valvular \\ Heart Disease Writing Group \\ Co-Chair, Appropriate Use Criteria Task Force
}

\section{INTRODUCTION}

Improvements in cardiovascular imaging technology and their broader application to cardiovascular diagnosis and therapy have led to a sharp increase in cardiovascular imaging. Diagnostic imaging services reimbursed under Medicare's physician fee schedule grew more rapidly than any other type of physician service from 1999 to 2003, although more recently, the rate of imaging volume growth in Medicare has been slowing. Still, the armamentarium of noninvasive diagnostic tools has expanded greatly, offering a variety of new and more sophisticated imaging techniques. As imaging technologies and clinical applications continue to advance, the healthcare community must understand how best to incorporate these technologies into daily clinical care and how to choose between new and established imaging technologies.

Using standardized methodology, the clinical scenarios (indications) in this document were developed by a diverse writing group to represent patient presentations encountered in everyday practice and were evaluated and rated by a separate, independent rating panel.

Because there is significant clinical overlap between valvular and structural heart disease, separating the indications in the 2 AUC documents is somewhat arbitrary. The writing group therefore deliberately followed a common structure in creating the companion documents on valvular heart disease (VHD) and structural heart disease.

Specifically, this document is organized into 3 sections and 8 tables. Section 1. describes scenarios of initial evaluation with no prior imaging. Table 3 lists scenarios for the asymptomatic patient, whereas Table 4 lists scenarios for the symptomatic patient. Section 2 describes scenarios of sequential evaluation where prior imaging has been performed. Table 5 rates scenarios in which additional testing is used to clarify the initial diagnosis. Where the initial imaging modality is assumed to be transthoracic echocardiography (TTE), TTE is grayed out and eliminated as a further option. Tables 6 and 7 describe scenarios in which additional 
testing is used in the context of clinical follow-up after the initial diagnosis. Table 6 describes scenarios in which additional testing is performed in asymptomatic patients or patients with stable symptoms to assess stability or change of valvular or myocardial function. Table 7 describes scenarios in which follow-up testing is done in patients with worsening symptoms or to assess response to therapy. Table 8 includes indications for patients undergoing follow-up imaging after surgical valve replacement or repair. Section 3 evaluates percutaneous aortic valve replacement (Tables 9, 10,11) and mitral valve repair (Tables 12, 13, 14). Tables 9, 10, 11, 12,13 and 14 are further divided into preprocedural, intraprocedural, and postprocedural indications.

\section{METHODS}

\section{Indication Development}

This document addresses the appropriate use of multiple imaging modalities for clinical management of VHD. A standardized approach was used to create different categories of indications with the goal of capturing actual real-world clinical scenarios. ${ }^{1-3}$ Indications were created to cover established and emerging (specifically percutaneous structural interventions) treatment approaches for VHD.

To identify and categorize the scenarios, a multidisciplinary writing group of experts in the fields of cardiovascular imaging and VHD was convened. The group included representatives from a variety of related professional organizations and societies. Wherever possible during the writing process, the group members would map the scenarios to relevant clinical guidelines and key publications or references (see the Online Appendix). This included diagnosis-oriented guidelines ${ }^{4-10}$ and imaging-modality-specific guidelines. ${ }^{11-14}$ After the scenarios were formed, they were reviewed and critiqued by the parent AUC Task Force and by numerous external reviewers, including interventional cardiologists, cardiac surgeons, imaging experts, and internists. After the writing group incorporated this initial feedback, the scenarios were sent to an independent rating panel to ensure an appropriate balance of specialized expertise and general practice in the rating panel. ${ }^{2}$ By design, the rating panel comprised a combination of experts in the cardiovascular realm but also members with more general expertise, including internists and an outcomes researcher. The inclusion of generalists is intended to prevent bias in the scoring process, as specialists might have a natural tendency to rate the indications within their specialty as more appropriate than might nonspecialists. The rating panel was provided with a standardized rating package that included relevant evidence, and formal roles were established for facilitating panel interaction at the subsequent face-to-face meeting. Care was taken in providing objective, nonbiased information, including guidelines and key references. Although panel members were not provided explicit cost information to help determine their appropriate use ratings, they were asked to implicitly consider cost as an additional factor in their evaluation of appropriate use. In rating these criteria, the AUC Rating Panel was asked to assess whether the use of the test for each scenario was Appropriate (A), May Be Appropriate (M), or Rarely Appropriate (R) (see definitions in the following text).

The members of the rating panel first evaluated the indications independently (first-round rating). Then, the panel was convened for a face-to-face meeting to discuss each indication. At this meeting, panel members were given their scores and a blinded summary of their peers' scores. Following the meeting, panel members were asked again to independently provide scores for each indication (second-round rating). The second-round rating results were sent back to the writing group for additional vetting. At this point, the writing group had a final chance to clarify indications and, if necessary, return to the rating panel for rescoring. A detailed description of the methods used for rating the selected clinical indications is found in a previous publication, "ACCF Proposed Method for Evaluating the Appropriateness of Cardiovascular Imaging', , as well as in the updated version of this publication, "Appropriate Use of Cardiovascular Technology: 2013 ACCF Appropriate Use Criteria Methodology Update', ${ }^{2}$ Based on these multiple rounds of review and revision, each scenario was rated and classified as either Appropriate, May Be Appropriate, or Rarely Appropriate, using the following definition of appropriate use:

An appropriate imaging study is one in which the expected incremental information, combined with clinical judgment, exceeds the expected negative consequences by a sufficiently wide margin for a specific indication that the procedure is generally considered acceptable care and a reasonable approach for the indication.

Median Score 7 to 9: Appropriate test for specific indication (test is generally acceptable and is a reasonable approach for the indication).

An appropriate option for management of patients in this population due to benefits generally outweighing risks; an effective option for individual care plans, although not always necessary depending on physician judgment and patientspecific preferences (i.e., procedure is generally acceptable and is generally reasonable for the indication).

Median Score 4 to 6: May Be Appropriate test for specific indication (test may be generally acceptable and may be a reasonable approach for the indication). May Be Appropriate also implies that more research and/or patient information is needed to classify the indication definitively.

At times an appropriate option for management of patients in this population due to variable evidence or agreement regarding the benefit-risk ratio, potential benefit based on practice experience in the absence of evidence, and/or variability in the population; effectiveness for individual care must be determined by a patient's physician in consultation with the patient based on additional clinical variables and judgment along with patient preferences (i.e., procedure may be acceptable and may be reasonable for the indication). 
Median Score 1 to 3: Rarely Appropriate test for specific indication (test is not generally acceptable and is not a reasonable approach for the indication).

Rarely an appropriate option for management of patients in this population due to the lack of a clear benefit/risk advantage; rarely an effective option for individual care plans; exceptions should have documentation of the clinical reasons for proceeding with this care option (i.e., procedure is not generally acceptable and is not generally reasonable for the indication).

The division of the numerical scores into 3 levels of appropriateness is somewhat arbitrary, and the numeric designations should be viewed as a continuum. Further, clinical opinions may vary for particular clinical scenarios, such that scores in the intermediate level of appropriate use were labeled “May Be Appropriate,'” as critical patient or research data may be lacking or discordant. This designation should be a prompt to the field to carry out definitive research investigation whenever possible. It is anticipated that the AUC reports will continue to be revised as further data are generated and information from implementation of the criteria is accumulated.

The level of agreement among panelists as defined by RAND was analyzed on the basis of the BIOMED rule for a panel of 14 to 17 members. ${ }^{3}$ Thus, an agreement regarding an indication was considered to exist when 4 or fewer panelists' ratings fell outside of the 3-point region containing the median score.

Disagreement was defined as when at least 5 panelists' ratings fell in both the Appropriate and the Rarely Appropriate categories. Any indication having disagreement was categorized as May Be Appropriate regardless of the final median score.

\section{GENERAL ASSUMPTIONS}

1. This document will address the use of multimodality imaging for the evaluation and treatment of VHD.

2. Indication ratings contained herein supersede the ratings of similar indications contained in previous AUC documents.

3. Evaluation of all indications pertains only to nonurgent clinical circumstances.

4. For the purposes of this document, which evaluates cardiovascular imaging, cardiac catheterization/angiography did not include the assessment of hemodynamics when this modality was rated.

5. A qualified clinician has obtained a complete clinical history and performed a physical examination so that the clinical status of the patient can be assumed to be valid as stated in the indication. Example: an asymptomatic patient is truly asymptomatic, and sufficient questioning has been undertaken for the condition in question.

6. All patients are receiving optimal standard care, including guideline-based risk factor modification, primary and secondary prevention of ischemic heart disease, or treatment of heart failure unless it is specifically noted otherwise.

7. The indications are, at times, intended to be broad to cover an array of cardiovascular signs and symptoms and to account for the ordering physician's best judgment as to the presence of cardiovascular abnormalities. Additionally, there are likely clinical scenarios that are not covered in this document.

8. If the reason for a test can be assigned to more than 1 indication, it is classified under the most clinically significant indication.

9. Testing modalities are rated for their level of appropriateness specific to clinical scenarios rather than a forced rank order comparison against other testing modalities. The goal of this document is to identify any and all tests that are considered reasonable for a given clinical indication. Determination of the range of modalities that may or may not be reasonable for specific indications is the goal of this document rather than determining a single best test for each indication or a rank order. As such, more than 1 test type may be considered Appropriate, May Be Appropriate, or Rarely Appropriate for any given clinical indication.

10. If more than 1 modality falls into the same appropriate use category, physician judgment and available local expertise should be used to determine the choice of test.

11. The appropriate use of testing is presumed to have the potential to affect clinical decision making and to direct therapeutic interventions.

12. Patients are suitable candidates for the procedure after consideration of procedural risk. Unless explicitly stated, it is presumed that patients presenting for a specific clinical indication are potential candidates for all tests to be rated and do not present with strong contraindications that preclude them from being tested (e.g., renal dysfunction, presence of an implanted device). It is further noted that appropriateness ratings may not be generalized to all populations. Patients in the elderly or very elderly populations, for example, may not have been adequately studied in clinical trials. This is especially true in such patients with VHD and multiple medical comorbidities.

13. Risk benefit: Overall patients' representation (age, comorbidities, and so on) was used in the risk/ benefit calculation. Each modality considered in this document has inherent risks that may include but are not limited to radiation exposure, contrast sensitivity, other bodily injury, and interpretation 
errors. For any test, there may be certain patient populations that are more susceptible to its known risks that are not specifically captured in the indications but deserve consideration when rating. Such risks should be viewed "on balance" and not used as justification to systematically reduce the level of appropriateness of a particular test compared with other tests. (e.g., tests that expose the patient to ionizing radiation should not necessarily receive a lower score than those that do not). Thus, a given modality should be weighed specifically in the context of the clinical scenario with the potential harm considered relative to the potential benefit gained.

14. Radiation safety: No clinical evidence to date unequivocally supports the notion that low-dose ionizing radiation at the levels used in medical imaging is associated with an increased long-term risk of malignancy. In a conservative approach, many experts in the field have adopted the linear nothreshold hypothesis, which assumes a linear relationship between radiation dose and the risk of malignancy irrespective of the magnitude of the radiation dose. Accordingly, the following radiation safety principles should be applied to all testing involving ionizing radiation. ${ }^{15}$

Clinical benefit should be as high as reasonably achievable (AHARA), embracing the guiding principle that testing should be performed on cohorts that are most likely to experience a net benefit.

- Radiation exposure should be as low as reasonably achievable (ALARA). ALARA should be used to guide test choice and the imaging protocol. Implicit in the ALARA principle is that the use of tests involving ionizing radiation should be minimized in vulnerable populations such as younger patients, and that optimal test procedures are utilized to perform the test at the lowest possible radiation dose while preserving image quality and information output.

15. Selection of patients for and monitoring of patients during and after contrast administration are assumed to accord with published standards when available.

16. Cost: Clinical benefit should always be considered first, and cost should be considered in relationship to these benefits when determining net value. Example: a procedure with moderate clinical efficacy for a given AUC indication should not be scored as more appropriate than a procedure with a high clinical efficacy solely because of lower cost. Value may be informed by multiple measures of potential economic impact such as: a) induced downstream or layered testing rates; b) comparative cost savings or minimization for diagnostic or near-term follow-up; c) cost to reduce adverse outcomes (e.g., cost for hospitalization averted); and d) cost for life year gained.

17. All tests and procedures are presumed to be performed and interpreted by qualified individuals in a facility in compliance with national standards for performing such imaging studies or procedures. Therefore, the level of appropriateness does not consider issues of local availability or skill in the rating of any modality. ${ }^{16-20}$

18. Time biases in available data: Newer technologies should not be considered necessarily more or less appropriate than older technologies. Apparent differences in diagnostic accuracy and risk stratification between older and newer techniques may not be accurate, especially when the techniques are not compared directly or when historical data are utilized. As treatment paradigms evolve, diagnosis may occur at earlier stages of disease, posing unique challenges for comparison of the performance of diagnostic modalities used at different stages of the disease process, owing to time lag bias.

19. Patients are suitable candidates for the procedure, including the patient's risk from the procedure.

\section{DEFINITIONS}

\section{Family History}

In this document, the term "family history" refers to first-degree relatives only.

\section{Symptomatic}

A patient is deemed to be symptomatic when he/she exhibits typical signs and/or symptoms (e.g., for congestive heart failure, symptoms such as dyspnea, rales, edema, and limited exercise capacity).

\section{Asymptomatic}

Patient is deemed asymptomatic when he/she exhibits none of the typical symptoms.

\section{Low, Moderate, and High Pretest Probability} As defined by the "2013 ACC/AHA/AATS/PCNA/ SCAI/STS Focused Update of the Guideline for the Diagnosis and Management of Patients with Stable Ischemic Heart Disease" (6a). Low pretest probability indicates $<10 \%$ probability of disease prior to the test under consideration. Moderate 
Table 1. Stages of Valvular Heart Disease

\begin{tabular}{|c|c|c|}
\hline Stage & Definition & Description \\
\hline A & At risk & Patients with risk factors for development of VHD \\
\hline B & Progressive & $\begin{array}{l}\text { Patients with progressive VHD (mild-to-moderate severity and } \\
\text { asymptomatic) }\end{array}$ \\
\hline \multirow[t]{3}{*}{$\mathrm{C}$} & Asymptomatic severe & Asymptomatic patients who meet criteria for severe VHD: \\
\hline & & $\begin{array}{l}\text { C1: Asymptomatic patients with severe VHD in whom the left or right } \\
\text { ventricle remains compensated }\end{array}$ \\
\hline & & $\begin{array}{l}\text { C2: Asymptomatic patients with severe VHD with decompensation of the } \\
\text { left or right ventricle }\end{array}$ \\
\hline $\mathrm{D}$ & Symptomatic severe & Patients who have developed symptoms as a result of severe VHD \\
\hline
\end{tabular}

Reproduced from Nishimura et $\mathrm{al}^{5}$

$V H D$, valvular heart disease

pretest probability is a range of $10 \%$ to $90 \%$ pretest probability. High pretest probability is a $>90 \%$ likelihood of the presence of the disease entity under question prior to any testing.

\section{Clinically Significant}

An abnormality, that if left untreated, can or will lead to functional impairment or death.

\section{Mild, Moderate, and Severe Valvular Disease} As defined by the "2017 AHA/ACC Focused Update of the 2014 AHA/ACC Guideline for the Management of Patients with Valvular Heart Disease', 4

\section{Stages of VHD}

VHD as defined by the "2017 AHA/ACC Focused Update of the 2014 AHA/ACC Guideline for the Management of Patients with Valvular Heart Disease', (4,4a) (Table 1).

\section{Uninterpretable or Technically Limited Images} Images that are not of diagnostic quality despite performance of the study by a skilled sonographer, technician, or other provider using appropriate equipment. This may be due to patient-related factors such as body habitus or motion artifact.

\section{Nonsustained Ventricular Tachycardia}

Ventricular arrhythmia of 3 or more consecutive complexes but lasting $<30$ seconds in duration at a rate $>100 \mathrm{bpm}$.

\section{Sustained Ventricular Tachycardia}

Ventricular tachycardia lasting more than 30 seconds or requiring therapy because of hemodynamic compromise in $<30$ seconds.

\section{Syncope}

Transient loss of consciousness due to global cerebral hypoperfusion characterized by rapid onset, short duration, and spontaneous complete recovery, not lightheadedness or dizziness alone.

\section{Presyncope}

Near loss of consciousness.

\section{Heart Failure}

Signs and symptoms explainable on the basis of systolic or diastolic dysfunction.

\section{Heart Failure Stages A, B, C, and D}

Heart failure as defined by the "2009 Focused Update Incorporated into the ACC/AHA 2005

Table 2. Stages of Heart Failure

\section{Stage}

\section{Definition}

Stage A Patients with risk factors for heart failure but without structural disease or symptoms (e.g., patient with hypertension but without left ventricular hypertrophy).

Stage B Patient with structural disease but no symptoms (e.g., asymptomatic left ventricular hypertrophy)

Stage C Current or prior symptoms of heart failure

Stage D Drug-refractory heart failure 
Guidelines for the Diagnosis and Management of Heart Failure in Adults" 6 (Table 2).

\section{Indication}

Synonymous with scenario. A set of patient-specific conditions defines "indication." The term clinical indication does not necessarily imply that testing is warranted. In other words, for some clinical indications, all modalities may be rated as Rarely Appropriate.

16. Low-Flow, Low-Gradient Valvular Aortic Stenosis

Severe aortic stenosis (AS) by valve area in the presence of a low transaortic volume flow rate due to either left ventricular (LV) systolic dysfunction with a low LV ejection fraction (stage D2) or to a small hypertrophied LV with a low stroke volume (stage D3, also known as paradoxical low-flow AS).

\section{Primary Mitral Regurgitation}

Mitral regurgitation (MR) related to pathology of at least 1 of the components of the valve (leaflets, chordae tendineae, papillary muscles, or annulus) resulting in valve incompetence.

\section{Secondary MR}

MR in the presence of a relatively normal mitral valve, related to LV dysfunction caused by coronary artery disease, myocardial infarction (ischemic chronic secondary MR), or idiopathic myocardial disease (nonischemic chronic secondary MR). The abnormal and dilated LV causes papillary muscle displacement, which in turn results in leaflet tethering and/or associated annular dilation that prevents coaptation.

\section{ABBREVIATIONS}

$\mathrm{AS}=$ aortic stenosis

AUC $=$ appropriate use criteria

$\mathrm{CCT}=$ cardiac computed tomography

$\mathrm{LV}=$ left ventricle/left ventricular

$\mathrm{MR}=$ mitral regurgitation

TAVR $=$ transcatheter aortic valve replacement

TEE $=$ transesophageal echocardiography

TTE $=$ transthoracic echocardiography

$\mathrm{VHD}=$ valvular heart disease

\section{MULTIMODALITY IMAGING IN VHD: APPROPRIATE USE CRITERIA (BY INDICATION)}

\section{Section 1: Initial Evaluation for VHD}

See Tables 3 and 4 .

\section{Section 2: Prior Testing}

See Tables 5, 6, 7, and 8 .

\section{Section 3: Transcatheter Intervention for VHD}

See Tables 9, 10, 11, 12, 13, and 14.

Table 3. Initial Evaluation of an Asymptomatic Patient

\begin{tabular}{|c|c|c|c|c|c|c|}
\hline \multicolumn{2}{|c|}{ Indication } & \multirow{2}{*}{$\begin{array}{c}\text { TTE } \\
\text { A (9) }\end{array}$} & \multirow{2}{*}{$\begin{array}{c}\begin{array}{c}\text { TEE (With } \\
\text { Possible 3D) }\end{array} \\
\text { R (2) }\end{array}$} & \multirow{2}{*}{$\frac{\text { 3D TTE }}{\text { R (3) }}$} & \multirow{2}{*}{$\begin{array}{l}\text { CMR } \\
R(2)\end{array}$} & \multirow{2}{*}{$\begin{array}{l}\text { CCT } \\
R(1)\end{array}$} \\
\hline 1. & - Unexplained murmur or abnormal heart sounds & & & & & \\
\hline 3. & - History of rheumatic heart disease & A (9) & $\mathbf{R}(3)$ & M (4) & R (1) & $\mathbf{R}(\mathbf{1})$ \\
\hline 4. & - Known systemic or acquired disease associated with VHD & A (9) & R (2) & R (3) & R (3) & $\mathbf{R}(\mathbf{2})$ \\
\hline 6. & $\begin{array}{l}\text { - Exposure to medications that could result in } \\
\text { development of VHD }\end{array}$ & A (7) & $\mathbf{R}(\mathbf{1})$ & $R(1)$ & $\mathbf{R}(1)$ & $R(\mathbf{1})$ \\
\hline
\end{tabular}

3D, 3-dimensional; $A$, appropriate; $C C T$, cardiac computed tomography; $C M R$, cardiovascular magnetic resonance imaging; $M$, may be appropriate; $R$, rarely appropriate; $T E E$, transesophageal echocardiography; $T T E$, transthoracic echocardiography; $V H D$ valvular heart disease 
Table 4. Initial Evaluation of a Patient with Clinical Signs and/or Symptoms

\begin{tabular}{|c|c|c|c|c|c|c|c|c|c|c|c|}
\hline \multicolumn{2}{|c|}{ Indication } & TTE & $\begin{array}{l}\text { TEE (With } \\
\text { Possible 3D) }\end{array}$ & 3D TTE & EX.-SE & DSE & RVG & FDG-PET & $\begin{array}{c}\text { MPI } \\
\text { (SPECT/PET) }\end{array}$ & CMR & CCT \\
\hline \multicolumn{12}{|c|}{ Arrhythmias } \\
\hline 7. & $\begin{array}{l}\text { - Palpitations AND } \\
\text { No other symptoms or } \\
\text { signs of cardiovascular } \\
\text { disease }\end{array}$ & M (4) & $\mathbf{R}(\mathbf{1})$ & $R(1)$ & $R(1)$ & $R(1)$ & $R(1)$ & & $R$ (1) & $R$ (1) & $\mathbf{R}$ (1) \\
\hline \multicolumn{12}{|c|}{ Presyncope/Syncope } \\
\hline 8. & $\begin{array}{l}\text { - Presyncope AND } \\
\text { - No other symptoms or signs } \\
\text { of cardiovascular disease }\end{array}$ & M (6) & R (1) & $\mathrm{R}(\mathbf{1})$ & $\mathrm{R}(\mathbf{1})$ & $\mathrm{R}(\mathbf{1})$ & $\mathrm{R}(\mathbf{1})$ & & R (1) & $\mathrm{R}(1)$ & $R(1)$ \\
\hline 9. & $\begin{array}{l}\text { - Syncope AND } \\
\text { - No other symptoms or signs } \\
\text { of cardiovascular disease }\end{array}$ & $A(8)$ & $R(1)$ & $R(1)$ & M (4) & $R(1)$ & $R(1)$ & & $R$ (2) & $R(3)$ & $\mathrm{R}(1)$ \\
\hline \multicolumn{12}{|c|}{ Hypotension or Hemodynamic Instability } \\
\hline 10. & $\begin{array}{l}\text { - Hypotension or hemodynamic } \\
\text { instability AND } \\
\text { - Uncertain or suspected } \\
\text { cardiac etiology }\end{array}$ & $A(9)$ & R (3) & $R(1)$ & $R(1)$ & $R$ (1) & $\mathbf{R}$ (1) & & $R$ (1) & $R(1)$ & $R(1)$ \\
\hline 11. & $\begin{array}{l}\text { - Assessment of volume status } \\
\text { in a critically ill patient }\end{array}$ & M (6) & $R$ (2) & $R(1)$ & $R(1)$ & $R(1)$ & $R(1)$ & & $R$ (1) & $R(1)$ & $R$ (1) \\
\hline 12. & $\begin{array}{l}\text { - Suspected acute mitral or } \\
\text { aortic regurgitation }\end{array}$ & $A(9)$ & M (6) & R (3) & $R(1)$ & $\mathbf{R}$ (1) & $\mathbf{R}(\mathbf{1})$ & & $R$ (1) & $R(1)$ & R (2) \\
\hline \multicolumn{12}{|c|}{ Respiratory Failure } \\
\hline 13. & $\begin{array}{l}\text { - Respiratory failure or } \\
\text { hypoxemia of uncertain } \\
\text { etiology }\end{array}$ & $A(8)$ & M (4) & $R(2)$ & $R(1)$ & $R(1)$ & $R(1)$ & & $R(1)$ & $R(1)$ & M (5) \\
\hline 14. & $\begin{array}{l}\text { - Respiratory failure or } \\
\text { hypoxemia AND } \\
\text { - Noncardiac etiology of } \\
\text { respiratory failure has been } \\
\text { established }\end{array}$ & M (4) & $\mathbf{R}(\mathbf{1})$ & $R(1)$ & $R(1)$ & $\mathrm{R}$ (1) & $\mathbf{R}(\mathbf{1})$ & & $\mathbf{R}(\mathbf{1})$ & $R(1)$ & $R(1)$ \\
\hline \multicolumn{12}{|c|}{ Heart Failure } \\
\hline 15. & $\begin{array}{l}\text { - Initial evaluation in patients } \\
\text { presented with } \mathrm{HF} \text { to exclude } \\
\text { the presence of primary or } \\
\text { secondary valve disease }\end{array}$ & $A(9)$ & R (3) & $R(3)$ & $R$ (1) & $\mathrm{R}(1)$ & $R(1)$ & & $R(1)$ & $R$ (3) & $\mathbf{R}(1)$ \\
\hline \multicolumn{12}{|c|}{ Bacteremia/Endocarditis } \\
\hline 16. & $\begin{array}{l}\text { - Suspected IE (native } \\
\text { valve, prosthetic valve, } \\
\text { endocardial lead) AND } \\
\text { - Positive blood cultures or } \\
\text { a new murmur }\end{array}$ & $A(9)$ & A (8) & M (4) & $R(1)$ & $R(1)$ & $\mathbf{R}$ (1) & R (3) & $R$ (1) & R (2) & R (3) \\
\hline 17. & $\begin{array}{l}\text { - Transient fever AND } \\
\text { - No evidence of bacteremia or } \\
\text { a new murmur }\end{array}$ & $\mathbf{R}(\mathbf{2})$ & R (1) & R (1) & $\mathrm{R}(\mathbf{1})$ & $\mathbf{R}(1)$ & $\mathbf{R}(\mathbf{1})$ & $\mathbf{R}(\mathbf{1})$ & R (1) & R (1) & $\mathrm{R}(1)$ \\
\hline 18. & $\begin{array}{l}\text { - Transient bacteremia AND } \\
\text { - Pathogen not typically } \\
\text { associated with IE } \\
\text { and/or a documented } \\
\text { nonendovascular source } \\
\text { or infection }\end{array}$ & $\mathrm{R}(3)$ & $\mathbf{R}(\mathbf{1})$ & $R(1)$ & $R(1)$ & $\mathbf{R}(\mathbf{1})$ & $\mathbf{R}(\mathbf{1})$ & R (1) & $R$ (1) & $R(1)$ & $R(1)$ \\
\hline \multicolumn{12}{|c|}{ Cardiac Mass/Cardiac Source of Emboli } \\
\hline 19. & $\begin{array}{l}\text { - Suspected cardiac mass, sus- } \\
\text { pected tumor or thrombus, or } \\
\text { potential cardiac source of } \\
\text { emboli }\end{array}$ & $A(9)$ & $A(7)$ & M (5) & $R(1)$ & $R(1)$ & $\mathbf{R}(\mathbf{1})$ & R (1) & $R(1)$ & M (6) & M (6) \\
\hline
\end{tabular}

3D, 3-dimenstional; $A$, appropriate; $C C T$, cardiac computed tomography; $C M R$, cardiovascular magnetic resonance imaging; $D S E$, dobutamine stress echocardiography; Ex.-SE, exercise stress echocardiography; FDG-PET, fluorodeoxyglucose-positron emission tomography; $H F$, heart failure; $I E$, infective endocarditis; $M$, may be appropriate; $M P I$, myocardial perfusion imaging; $P E T$, positron emission tomography; $R$, rarely appropriate; $R V G$, radionuclide ventriculography; SPECT, single-photon emission computed tomography; TEE, transesophageal echocardiography; TTE, transthoracic echocardiography 
Table 5. Additional Testing to Clarify Diagnosis

\begin{tabular}{|c|c|c|c|c|c|c|c|c|c|c|c|c|c|c|c|}
\hline Indic & cation & TTE & $\begin{array}{c}\text { TTE } \\
\text { With } \\
\text { Contrast }\end{array}$ & $\begin{array}{l}\text { TEE } \\
\text { (With } \\
\text { Possible } \\
\text { 3D) }\end{array}$ & 3D TTE & EX.-SE & DSE & $\begin{array}{l}\text { Low-Dose } \\
\text { DSE }\end{array}$ & RVG & $\begin{array}{l}\text { FDG- } \\
\text { PET }\end{array}$ & $\begin{array}{c}\text { MPI } \\
\text { (SPECT/ } \\
\text { PET) }\end{array}$ & CMR & CCT & ANG & Fluoro \\
\hline \multicolumn{16}{|c|}{ Inadequate TTE Images } \\
\hline 20. & $\begin{array}{l}\text { Inadequate TTE images for } \\
\text { the evaluation of possible } \\
\text { valvular heart disease due to } \\
\text { patient characteristics }\end{array}$ & & M (5) & A (8) & R (2) & $\mathbf{R}(\mathbf{1})$ & R (1) & $R(1)$ & $R(1)$ & & R (1) & M (6) & M (5) & $R$ (1) & R (1) \\
\hline 21. & $\begin{array}{l}\text { Characterization of native } \\
\text { or prosthetic valves with } \\
\text { clinical signs or symptoms } \\
\text { suggesting valve } \\
\text { dysfunction }\end{array}$ & & M (4) & A (8) & R (2) & $\mathbf{R}$ (1) & R (1) & R (1) & $R(1)$ & & R (1) & M (5) & M (6) & $R(2)$ & M (6) \\
\hline
\end{tabular}

Suspected Endocarditis With Negative TTE

22. - Suspected IE with moderate to high pretest probability (i.e., staph bacteremia,

fungemia, prosthetic heart valve, or intracardiac device)

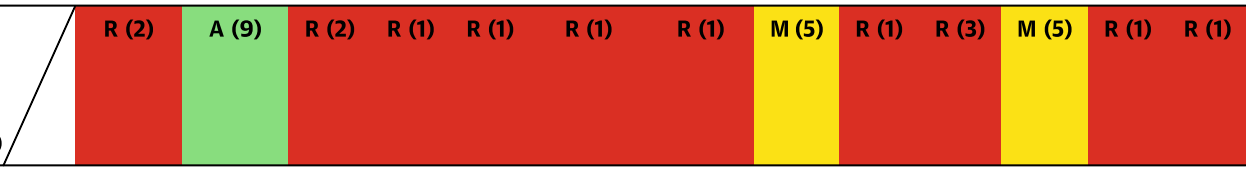

\section{Aortic Stenosis}

23. - Symptomatic, severe AS by calculated valve area (stage D2) AND

- Low flow/low gradient AND

- Low LVEF

24. - Severe AS, by calculated valve area AND

- Low flow/low gradient AND

- Preserved LVEF and for assessment of morphology, including calcification

25. - Moderate or asymptomatic severe AS (stages B and C), for measurement of changes in valve hemodynamics with exercise or pharmacological stress

26. - Symptomatic severe AS (stage D), for measurement of changes in valve hemodynamics with exercise or pharmacological stress

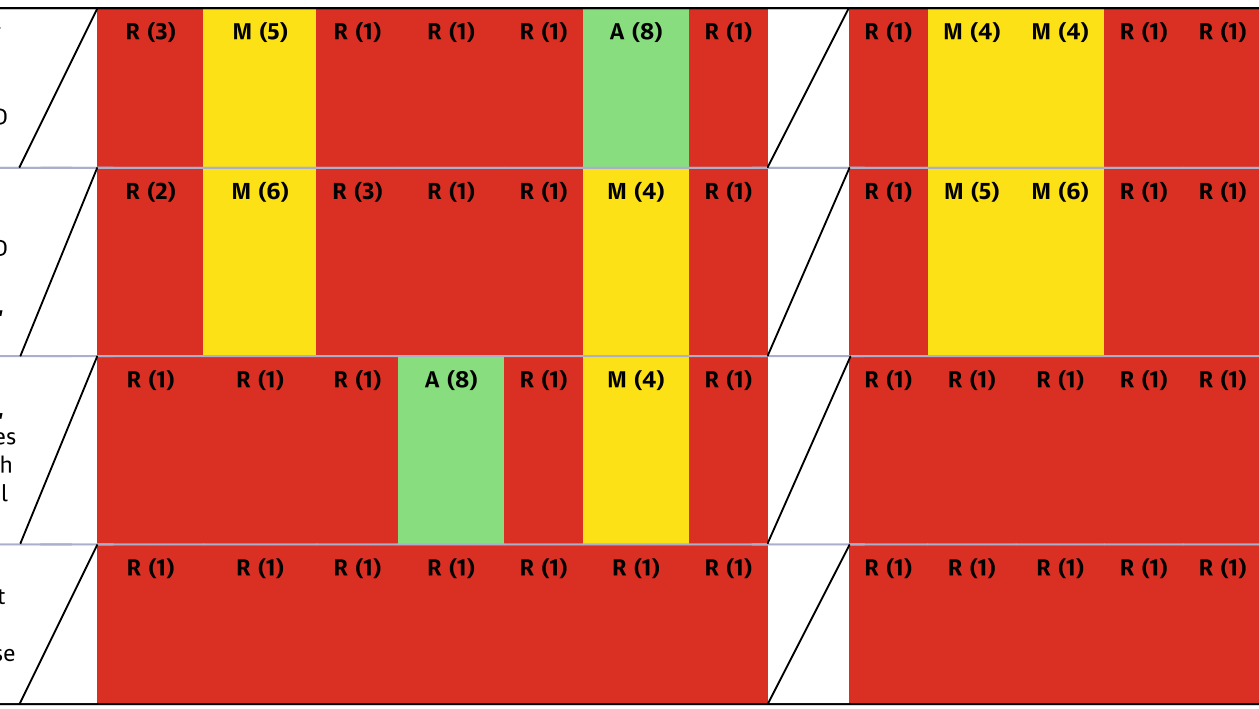

\section{Mitral Stenosis}

27. Discrepancy between resting Doppler echocardiographic findings and clinical symptoms or signs to evaluate mean mitral gradient and pulmonary artery pressure

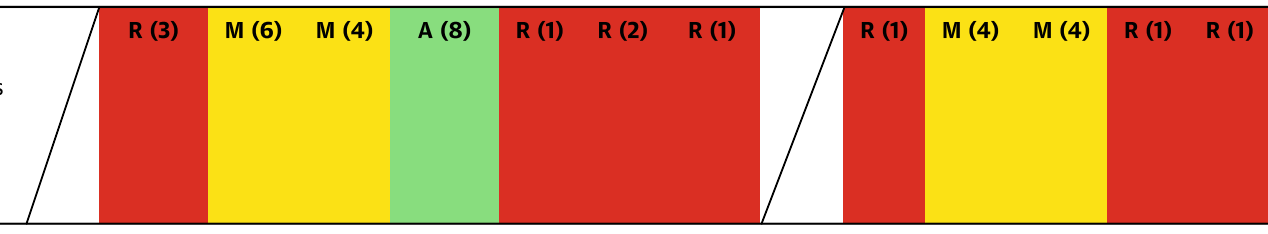

\section{Mitral Regurgitation}

28. - Severe MR suspected clinically AND

- Potentially underestimated on TTE despite optimal images

- Better imaging of MR jet needed

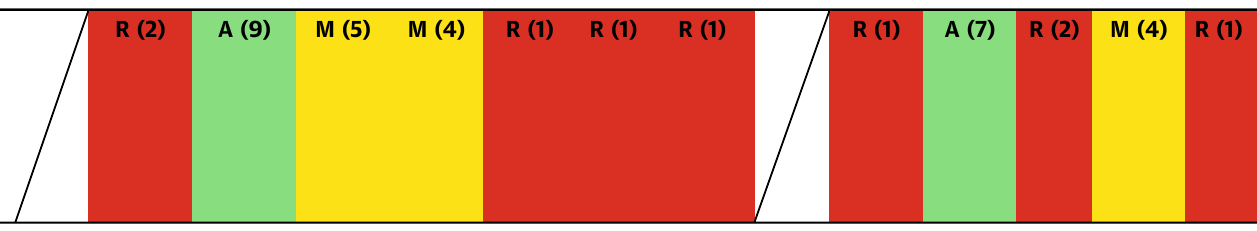


Table 5. continued

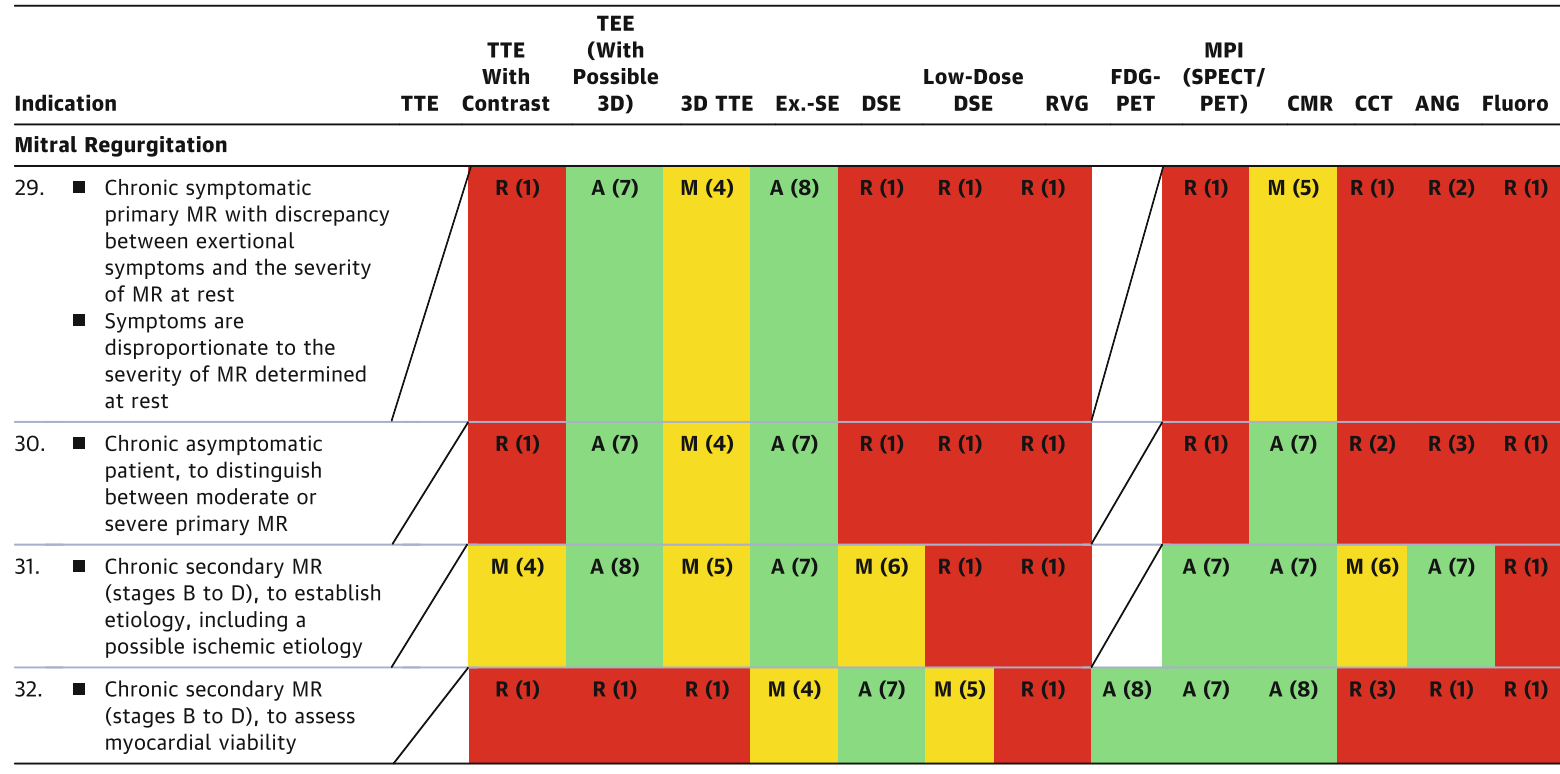

Aortic Regurgitation

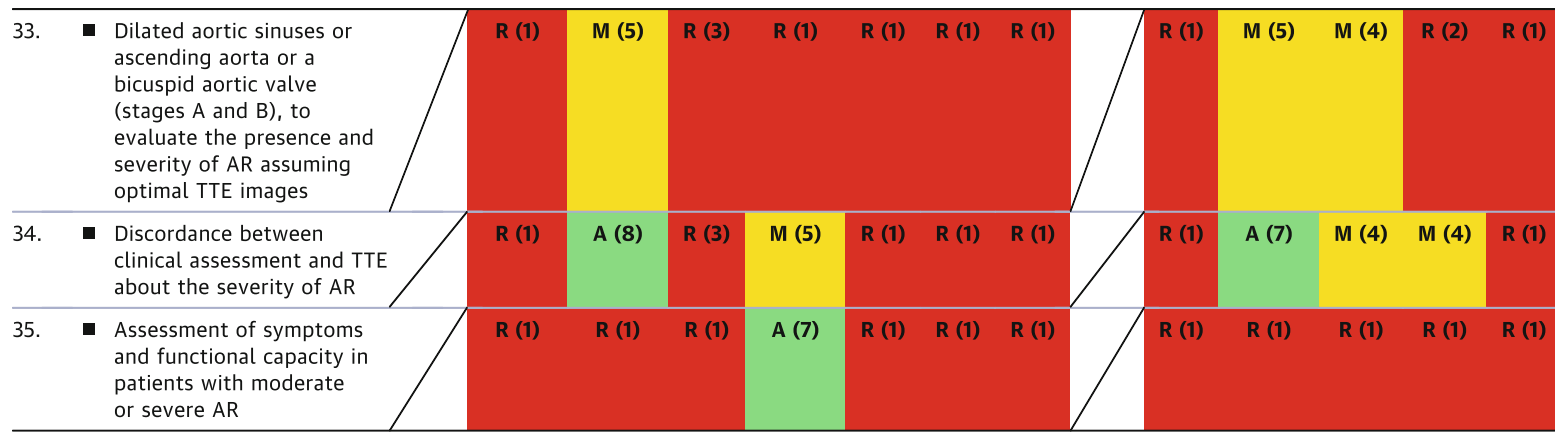

Other Valvular Regurgitation

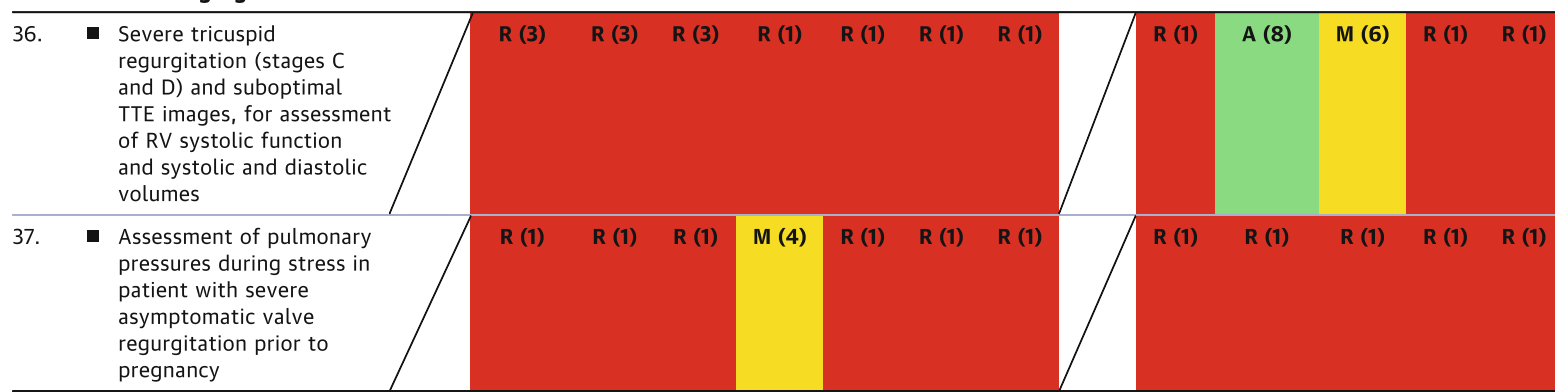

Valvular Mass

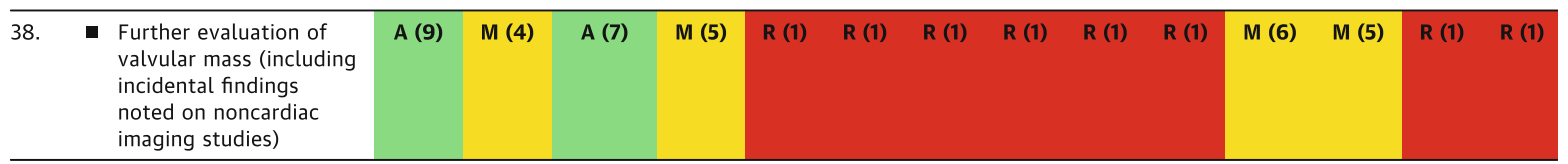

3D, 3-dimensional; $A$, appropriate; $A N G$, invasive coronary angiography/ventriculography/aortography; $A R$, aortic regurgitation; $A S$, aortic stenosis; $C C T$, cardiac computed tomography; $C M R$, cardiovascular magnetic resonance imaging; $D S E$, dobutamine stress echocardiography; Ex.-SE, exercise stress echocardiography; FDG-PET, fluorodeoxyglucose-positron emission tomography; Fluoro, fluoroscopy; $I E$, infective endocarditis; $L V E F$, left ventricular ejection fraction; $M$, may be appropriate; $M P I$, myocardial perfusion imaging; $M R$, mitral regurgitation; $P E T$, positron emission tomography; $R$, rarely appropriate; $R V G$, radionuclide ventriculography; SPECT, single photon emission computed tomography; TEE, transesophageal echocardiography; TTE, transthoracic echocardiography 
Table 6. Sequential or Follow-Up Testing: Asymptomatic or Stable Symptoms

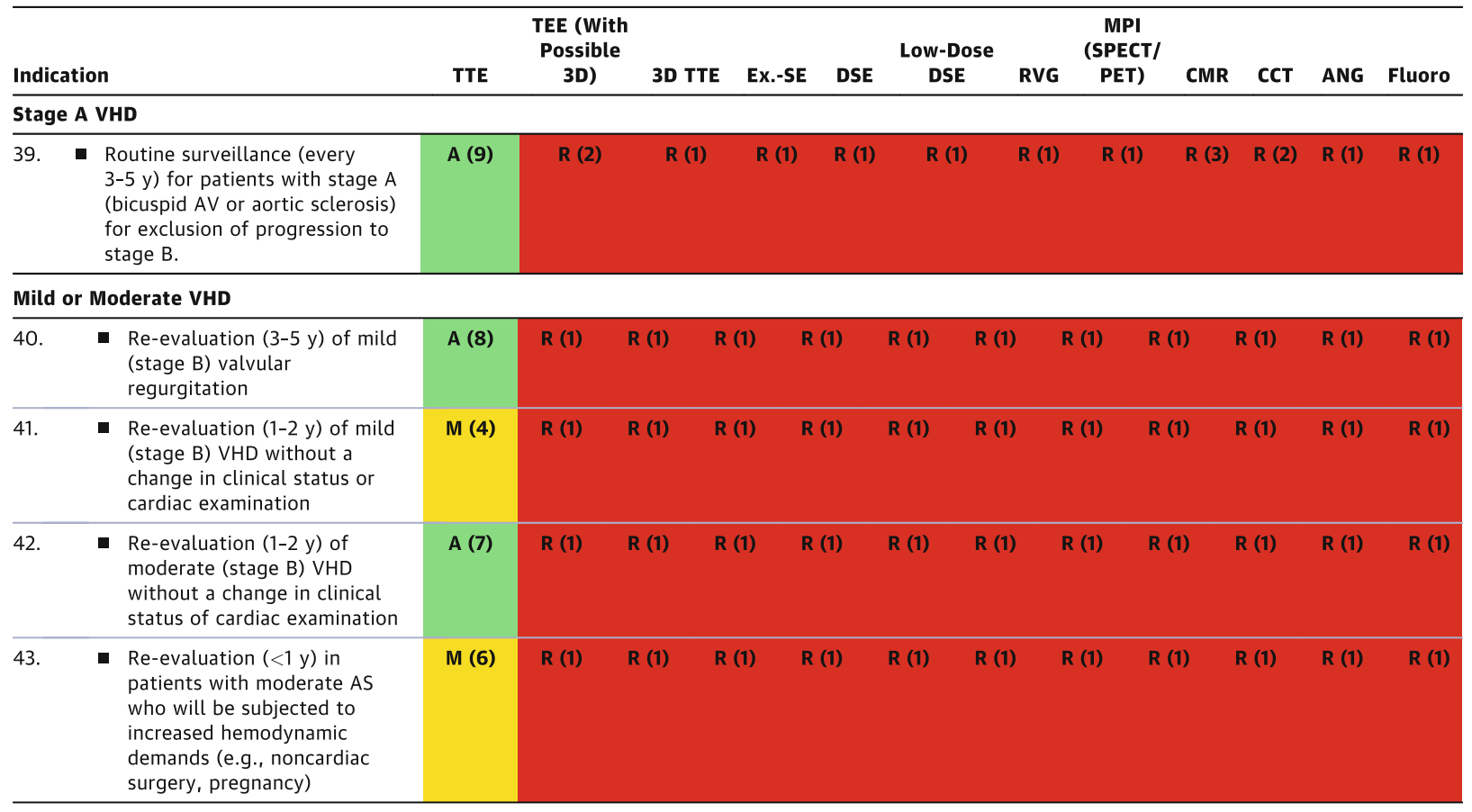

\section{Severe VHD}

\begin{tabular}{|c|c|c|c|c|c|c|c|c|c|c|c|c|c|}
\hline 44. & $\begin{array}{l}\text { Re-evaluation (6-12 m) of } \\
\text { asymptomatic severe (stage } \\
\text { C1) AS without a change in } \\
\text { clinical status or cardiac } \\
\text { examination }\end{array}$ & M (6) & R (1) & R (1) & R (3) & R (1) & R (1) & R (1) & R (1) & $R(1)$ & R (1) & R (1) & R (1) \\
\hline 45. & $\begin{array}{l}\text { Re-evaluation (every } 1 \text { y) for } \\
\text { asymptomatic (stage C1) } \\
\text { patients with AS }\end{array}$ & A (8) & $R$ (1) & R (1) & M (4) & R (1) & R (1) & R (1) & R (1) & $R(1)$ & R (1) & R (1) & R (1) \\
\hline 46. & $\begin{array}{l}\text { Re-evaluation }(6-12 \mathrm{~m}) \text { of } \\
\text { stage C1 patients with } \\
\text { asymptomatic severe AR with } \\
\text { preserved ejection fraction } \\
\text { and normal LV size }\end{array}$ & M (6) & $R(1)$ & $R(1)$ & $R(1)$ & $R$ (1) & $R$ (1) & $R(1)$ & $R$ (1) & $R(1)$ & $R(1)$ & $R(1)$ & $R(1)$ \\
\hline 47. & $\begin{array}{l}\text { Re-evaluation (every 6-12 m) } \\
\text { of stage C1 patients with } \\
\text { asymptomatic severe MR }\end{array}$ & $A(7)$ & $R(1)$ & R (1) & $\mathrm{R}(3)$ & $R$ (1) & R (1) & $R(1)$ & R (1) & $R(1)$ & $R(1)$ & $R(1)$ & $R(1)$ \\
\hline 48. & $\begin{array}{l}\text { Re-evaluation }(<1 \text { y) in } \\
\text { patients with severe AS who } \\
\text { will be subjected to increased } \\
\text { hemodynamic demands (e.g., } \\
\text { noncardiac surgery, } \\
\text { pregnancy) }\end{array}$ & M (6) & $R(1)$ & $R(1)$ & R (1) & $R(1)$ & R (1) & $R$ (1) & R (1) & $R(1)$ & $R(1)$ & $R(1)$ & $R(1)$ \\
\hline 49. & $\begin{array}{l}\text { Re-evaluation after control of } \\
\text { hypertension in patients with } \\
\text { low-flow/low-gradient severe } \\
\text { AS with preserved LVEF }\end{array}$ & $A(7)$ & $R(1)$ & $R$ (1) & R (1) & $R(1)$ & $R$ (1) & $R$ (1) & R (1) & $R(1)$ & $R$ (1) & $R(1)$ & $R$ (1) \\
\hline \multicolumn{14}{|c|}{ Bicuspid AV With Dilated Aorta } \\
\hline 50. & $\begin{array}{l}\text { - Re-evaluation }(<1 \mathrm{y} \text { ) of the size } \\
\text { and morphology of the aortic } \\
\text { sinuses and ascending aorta in } \\
\text { patients with a bicuspid } \mathrm{AV} \text { and } \\
\text { an ascending aortic diameter } \\
>4 \mathrm{~cm} \text { with } 1 \text { of the following: } \\
\text { aortic diameter }>4.5 \mathrm{~cm} \\
\text { rapid rate of change in } \\
\text { aortic diameter } \\
\text { family history } \\
\text { (first-degree relative) of } \\
\text { aortic dissection }\end{array}$ & $A(7)$ & R (3) & R (1) & $R(1)$ & R (1) & $R(1)$ & R (1) & R (1) & $A(8)$ & $A(8)$ & $R(1)$ & R (1) \\
\hline
\end{tabular}


Table 6. continued

\begin{tabular}{|c|c|c|c|c|c|c|c|c|c|c|c|c|c|c|c|}
\hline \multicolumn{3}{|c|}{ Indication } & \multicolumn{4}{|c|}{$\begin{array}{l}\text { TEE (With } \\
\text { Possible }\end{array}$} & EX.-SE & DSE & \multicolumn{2}{|c|}{ Low-Dose } & $\begin{array}{c}\text { MPI } \\
\text { (SPECT/ } \\
\text { PET) }\end{array}$ & CMR & СCT & ANG & Fluoro \\
\hline \multicolumn{16}{|c|}{ Bicuspid AV With Dilated Aorta } \\
\hline 51. & $\begin{array}{l}\text { - Re-evaluation }(<1 \mathrm{y}) \text { of the } \\
\text { size and morphology of the } \\
\text { aortic sinuses and ascending } \\
\text { aorta in patients with a } \\
\text { bicuspid } A V \text { and an aortic } \\
\text { diameter of } 4.0-4.5 \mathrm{~cm} \\
\text { without any of the risk facto } \\
\text { listed in Indication } 50 \text {. }\end{array}$ & & R (2) & R (1) & & (1) & R (1) & $R$ (1) & R (1) & R (1) & R (1) & & (1) & R (1) & R (1) \\
\hline Indic & ation & TTE & $\begin{array}{r}\text { TEE } \\
\text { Pos: } \\
3\end{array}$ & $\begin{array}{l}\text { (With } \\
\text { sible } \\
\text { D) }\end{array}$ & 3D TTE & EX.-SE & DSE & $\begin{array}{c}\text { Low-Dose } \\
\text { DSE }\end{array}$ & e RVG & FDG-PET & $\begin{array}{c}\text { MPI } \\
\text { (SPECT/PET) }\end{array}$ & CMR & CCT & ANG & Fluoro \\
\hline \multicolumn{16}{|c|}{ Endocarditis } \\
\hline 52. & $\begin{array}{l}\text { - Re-evaluation of prior } \\
\text { TTE/TEE finding for interval } \\
\text { change (e.g., resolution of } \\
\text { vegetation after antibiotic } \\
\text { therapy) when no change in } \\
\text { therapy is anticipated }\end{array}$ & M (4) & & (1) & $R$ (1) & $R(1)$ & R (1) & R (1) & $R(1)$ & R (1) & $R$ (1) & R (1) & $R(1)$ & R (1) & $\mathrm{R}(\mathbf{1})$ \\
\hline 53. & $\begin{array}{l}\text { Re-evaluation of prior } \\
\text { TTE/TEE finding for interval } \\
\text { change (e.g., resolution of } \\
\text { vegetation after antibiotic } \\
\text { therapy) when a change in } \\
\text { therapy is anticipated }\end{array}$ & $A(8)$ & & (6) & R (3) & R (1) & R (1) & R (1) & R (1) & R (1) & R (1) & R (1) & R (1) & R (1) & R (1) \\
\hline 54. & $\begin{array}{l}\text { Re-evaluation of patient with } \\
\text { IE at high risk of progression } \\
\text { or complications (e.g., } \\
\text { extensive infective tissue/ } \\
\text { large vegetation on initial } \\
\text { echocardiogram, or } \\
\text { staphylococcal, enterococcal, } \\
\text { or fungal infections) in the } \\
\text { absence of clinical change }\end{array}$ & A (7) & & (6) & $R$ (1) & $\mathrm{R}(1)$ & R (1) & $R$ (1) & $R(1)$ & R (3) & $\mathrm{R}$ (1) & R (3) & $\mathrm{R}(2)$ & $R(1)$ & $R(1)$ \\
\hline
\end{tabular}

3D, 3-dimensional; $A$, appropriate; $A N G$, invasive coronary angiography/ventriculography/aortography; $A S$, aortic stenosis; $A V$, aortic valve; $C C T$, cardiac computed tomography; $C M R$, cardiovascular magnetic resonance imaging; $D S E$, dobutamine stress echocardiography; Ex.-SE, exercise stress echocardiography; FDG-PET, fluorodeoxyglucose-positron emission tomography; Fluoro, fluoroscopy; IE, infective endocarditis; $L V E F$, left ventricular ejection fraction; $M$, may be appropriate; $M P I$, myocardial perfusion imaging; $P E T$, positron emission tomography; $R$, rarely appropriate; $R V G$, radionuclide ventriculography; SPECT, single photon emission computed tomography; TEE, transesophageal echocardiography; TTE, transthoracic echocardiography

Table 7. Sequential or Follow-Up Testing of New or Worsening Symptoms or to Guide Therapy

\begin{tabular}{|c|c|c|c|c|c|c|c|c|c|c|c|c|c|c|}
\hline \multicolumn{2}{|c|}{ Indication } & TTE & $\begin{array}{l}\text { TEE (With } \\
\text { Possible } \\
\text { 3D) }\end{array}$ & 3D TTE & Ex.-SE & E DSE & $\begin{array}{c}\text { Low-Dos } \\
\text { DSE }\end{array}$ & se RVG & $\begin{array}{l}\text { FDG- } \\
\text { PET }\end{array}$ & $\begin{array}{c}\text { MPI } \\
\text { (SPECT/ } \\
\text { PET) }\end{array}$ & CMR & CCT & ANG & Fluoro \\
\hline \multicolumn{15}{|c|}{ General } \\
\hline 55. & $\begin{array}{l}\text { - Re-evaluation of known VHD } \\
\text { with a change in clinical status } \\
\text { or cardiac examination or to } \\
\text { guide therapy }\end{array}$ & A (9) & M (5) & $R$ (1) & $R$ (3) & $R(1)$ & $R$ (1) & $R$ (1) & & $\mathrm{R}(1)$ & $\mathrm{R}(3)$ & $\mathrm{R}$ (1) & $R(1)$ & $R(1)$ \\
\hline \multicolumn{15}{|c|}{ Endocarditis } \\
\hline 56. & $\begin{array}{l}\text { - Re-evaluation of IE in a patient } \\
\text { with a change in clinical status or } \\
\text { cardiac examination (e.g., new } \\
\text { murmur, embolism, persistent } \\
\text { fever, HF, abscess, or } \\
\text { atrioventricular heart block) }\end{array}$ & A (9) & A (8) & R (3) & $R$ (1) $\quad F$ & $\mathbf{R}(\mathbf{1})$ & $R$ (1) & R (1) & R (3) & $R$ (1) & M (4) & M (5) & $R$ (1) & $R$ (1) \\
\hline
\end{tabular}

3D, 3-dimensional; $A$, appropriate; $A N G$, invasive coronary angiography/ventriculography/aortography; $C C T$, cardiac computed tomography; $C M R$, cardiovascular magnetic resonance imaging; $D S E$, dobutamine stress echocardiography; $E x$.-SE, exercise stress echocardiography; FDG-PET, fluorodeoxyglucose-positron emission tomography; Fluoro, fluoroscopy; $H F$, heart failure; $I E$, infective endocarditis; $M$, may be appropriate; $M P I$, myocardial perfusion imaging; $P E T$, positron emission tomography; $R$, rarely appropriate; $R V G$, radionuclide ventriculography; SPECT, single-photon emission computed tomography; TEE, transesophageal echocardiography; TTE, transthoracic echocardiography; VHD, valvular heart disease 
Table 8. Postoperative Imaging After Surgical Valve Replacement or Repair

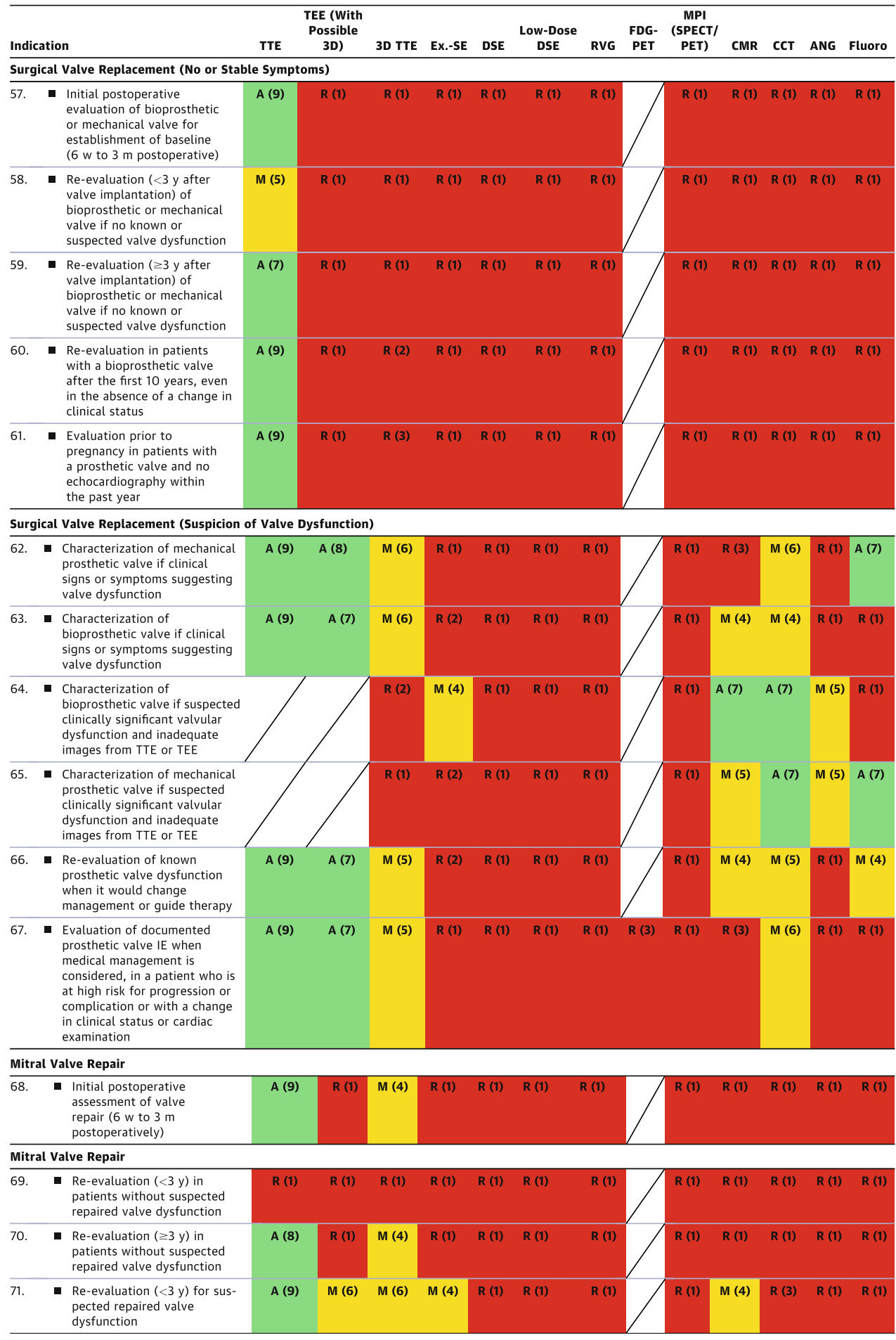

3D, 3-dimensional; $A$, appropriate; $A N G$, invasive coronary angiography/ventriculography/aortography; $C C T$, cardiac computed tomography; $C M R$, cardiovascular magnetic resonance imaging; DSE, dobutamine stress echocardiography; Ex.-SE, exercise stress echocardiography; FDG-PET, fluorodeoxyglucose-positron emission tomography; Fluoro, fluoroscopy; IE, infective endocarditis; $M$, may be appropriate; $M P I$, myocardial perfusion imaging; $P E T$, positron emission tomography; $R$, rarely appropriate; $R V G$, radionuclide ventriculography; SPECT, single photon emission computed tomography; TEE, transesophageal echocardiography; TTE, transthoracic echocardiography 
Table 9. Pre-TAVR Evaluation

\begin{tabular}{|c|c|c|c|c|c|c|c|c|c|c|c|c|c|c|}
\hline \multicolumn{3}{|c|}{ Indication } & \multirow{2}{*}{$\begin{array}{c}\text { TTE } \\
R(1)\end{array}$} & \multirow{2}{*}{$\begin{array}{c}\begin{array}{c}\text { TEE (With } \\
\text { Possible 3D) }\end{array} \\
R(1)\end{array}$} & \multirow{2}{*}{$\frac{\text { 3D TTE }}{\text { R (1) }}$} & \multirow{2}{*}{$\frac{\text { Ex.-SE }}{R(1)}$} & \multirow{2}{*}{$\begin{array}{l}\text { DSE } \\
\text { R (1) }\end{array}$} & \multirow{2}{*}{$\begin{array}{c}\text { Low-Dose } \\
\text { DSE } \\
\text { R (1) }\end{array}$} & \multirow{2}{*}{$\begin{array}{l}\text { RVG } \\
R(1)\end{array}$} & \multirow{2}{*}{$\begin{array}{c}\text { MPI } \\
\text { (SPECT/PET) } \\
\text { M (4) }\end{array}$} & \multirow{2}{*}{$\begin{array}{l}\text { CMR } \\
\mathbf{R}(1)\end{array}$} & \multirow{2}{*}{$\begin{array}{c}\text { CCT } \\
\text { M (5) }\end{array}$} & \multirow{2}{*}{$\begin{array}{l}\text { ANG } \\
\text { A (9) }\end{array}$} & \multirow{2}{*}{$\begin{array}{c}\text { Fluoro } \\
R(1)\end{array}$} \\
\hline 72. & - & $\begin{array}{l}\text { Assessment for concomitant } \\
\text { coronary artery disease }\end{array}$ & & & & & & & & & & & & \\
\hline 73. & - & $\begin{array}{l}\text { Accurate assessment of } \\
\text { annular size and shape* }\end{array}$ & R (3) & A (7) & M (4) & $R(1)$ & R (1) & $R(1)$ & R (1) & $R(1)$ & $A(7)$ & A (9) & R (1) & R (1) \\
\hline 74. & घ & $\begin{array}{l}\text { Assessment of number of } \\
\text { cusps and degree of } \\
\text { calcification }\end{array}$ & A (7) & A (7) & $M(6)$ & $R(1)$ & $R$ (1) & R (1) & $R(1)$ & R (1) & M (4) & A (9) & $R(1)$ & $R(1)$ \\
\hline 75. & - & $\begin{array}{l}\text { Measurement of the } \\
\text { distance between annulus } \\
\text { and the coronary ostia }\end{array}$ & R (1) & M (6) & $R(1)$ & $R(1)$ & $R(1)$ & $R(1)$ & $R(1)$ & R (1) & M (5) & A (9) & M (4) & $R(1)$ \\
\hline 76. & - & $\begin{array}{l}\text { Precise coaxial alignment of } \\
\text { the implant within the } \\
\text { centerline of the aortic valve }\end{array}$ & R (1) & R (3) & $R(1)$ & $R(1)$ & R (1) & $R(1)$ & R (1) & R (1) & $R(2)$ & $A(8)$ & R (1) & $R(1)$ \\
\hline 78. & घ & $\begin{array}{l}\text { Assessment of aortic } \\
\text { atherosclerotic burden }\end{array}$ & R (1) & M (5) & R (1) & $R(1)$ & R (1) & $R(1)$ & R (1) & R (1) & M (4) & A (9) & M (4) & R (1) \\
\hline 79. & $\boldsymbol{\square}$ & $\begin{array}{l}\text { Assessment of iliofemoral } \\
\text { vessels }\end{array}$ & $R(1)$ & $R(1)$ & $R(1)$ & R (1) & $R(1)$ & $R(1)$ & $R(1)$ & $R(1)$ & M (5) & $A(9)$ & M (5) & $\mathbf{R}(1)$ \\
\hline
\end{tabular}

3D, 3-dimensional; $A$, appropriate; $A N G$, invasive coronary angiography/ventriculography/aortography; $C C T$, cardiac computed tomography; $C M R$, cardiovascular magnetic resonance imaging; $D S E$, dobutamine stress echocardiography; Ex.-SE, exercise stress echocardiography; Fluoro, fluoroscopy; $M$, may be appropriate; MPI, myocardial perfusion imaging; PET, positron emission tomography; $R$, rarely appropriate; $R V G$, radionuclide ventriculography; $S P E C T$, single photon emission computed tomography; $T A V R$, transcatheter aortic valve replacement; TEE, transesophageal echocardiography; and TTE, transthoracic echocardiography ${ }^{*}$ Multimodality imaging might improve the accuracy of the measurements (1)

Table 10. Intraprocedural Evaluation During TAVR

\begin{tabular}{|c|c|c|c|c|c|c|}
\hline Indication & & TTE & $\begin{array}{c}\text { TEE (With } \\
\text { Possible 3D) }\end{array}$ & 3D TTE & ANG & Fluoro \\
\hline 80. & - Guidewire placement into the LV & $A(7)$ & $A(7)$ & M (5) & R (1) & A (9) \\
\hline 81. & - Valve placement & $A(7)$ & A (8) & M (6) & $A(7)$ & $A(9)$ \\
\hline 82. & - Postdeployment assessment (position, function, regurgitation) & $A(7)$ & A (8) & $A(7)$ & A (8) & A (7) \\
\hline 83. & $\begin{array}{l}\text { - Evaluate immediate complications } \\
\text { - Hypotension } \\
\text { - Coronary occlusion } \\
\text { - LV depression from rapid pacing } \\
\text { - LV outflow tract obstruction } \\
\text { - Severe MR } \\
\text { - Prosthesis dislodgment } \\
\text { - Tamponade } \\
\text { - Right ventricular perforation } \\
\text { - Air embolism } \\
\text { - Aortic dissection (paravalvular leak needs to be excluded) }\end{array}$ & $A(8)$ & $A(9)$ & $A(7)$ & A (8) & $A(8)$ \\
\hline
\end{tabular}

3D, 3-dimensional; $A$, appropriate; $A N G$, invasive coronary angiography/ventriculography/aortography; Fluoro, fluoroscopy; $L V$, left ventricle; $M$, may be appropriate; $R$, rarely appropriate; TAVR, transcatheter aortic valve replacement; $T E E$, transesophageal echocardiography; TTE, transthoracic echocardiography 
Table 11. Postprocedural Assessment After TAVR (Out of Procedure and $<30$ days)

\begin{tabular}{|c|c|c|c|c|c|c|c|c|c|c|c|c|}
\hline \multicolumn{2}{|c|}{ Indication } & \multirow{2}{*}{$\begin{array}{l}\text { TTE } \\
\text { A (8) }\end{array}$} & \multirow{2}{*}{$\begin{array}{c}\text { TEE (With } \\
\text { Possible } \\
\text { 3D) }\end{array}$} & \multirow{2}{*}{$\frac{\text { 3D TTE }}{\text { M (5) }}$} & \multirow{2}{*}{$\frac{\text { Ex.-SE }}{R(1)}$} & \multirow{2}{*}{$\begin{array}{l}\text { DSE } \\
\text { R (1) }\end{array}$} & \multirow{2}{*}{$\begin{array}{c}\text { Low-Dose } \\
\text { DSE } \\
\text { R (1) }\end{array}$} & \multirow{2}{*}{$\begin{array}{l}\text { RVG } \\
R(1)\end{array}$} & \multirow{2}{*}{$\begin{array}{c}\begin{array}{c}\text { MPI } \\
\text { (SPECT/PET) }\end{array} \\
R(1)\end{array}$} & \multirow{2}{*}{$\begin{array}{l}\text { CMR } \\
\text { M (4) }\end{array}$} & \multirow{2}{*}{$\frac{\text { CCT }}{M(4)}$} & \multirow{2}{*}{$\frac{\text { Brain CT/MRI }}{\mathrm{R}(1)}$} \\
\hline 84. & $\begin{array}{l}\text { Assessment of degree of } \\
\text { aortic regurgitation } \\
\text { (including valvular and } \\
\text { paravalvular) with suspicion } \\
\text { of valve dysfunction }\end{array}$ & & & & & & & & & & & \\
\hline 85. & $\begin{array}{l}\text { - Assessment of stroke with } \\
\text { suspicion of valve } \\
\text { dysfunction }\end{array}$ & $A(7)$ & M (6) & R (3) & $R(1)$ & R (1) & $R(1)$ & $R$ (1) & R (1) & $\mathrm{R}(1)$ & M (6) & A (9) \\
\hline
\end{tabular}

3D, 3-dimensional; $A$, appropriate; $A N G$, invasive coronary angiography/ventriculography/aortography; $C C T$, cardiac computed tomography; $C M R$, cardiovascular magnetic resonance imaging; $C T$, computed tomography; DSE, dobutamine stress echocardiography; Ex.-SE, exercise stress echocardiography; $M$, may be appropriate; $M P I$, myocardial perfusion imaging; $M R I$, magnetic resonance imaging; $R$, rarely appropriate; $R V G$, radionuclide ventriculography; TAVR, transcatheter aortic valve replacement; $T E E$, transesophageal echocardiography; TTE, transthoracic echocardiography

Table 12. Evaluation Prior to Percutaneous Mitral Valve Repair

\begin{tabular}{|c|c|c|c|c|c|c|c|c|}
\hline \multicolumn{3}{|c|}{ Indication } & \multirow{2}{*}{$\begin{array}{c}\text { TTE } \\
\text { A (8) }\end{array}$} & \multirow{2}{*}{$\begin{array}{c}\begin{array}{c}\text { TEE (With } \\
\text { Possible 3D) }\end{array} \\
\text { A (9) }\end{array}$} & \multirow{2}{*}{$\begin{array}{c}\text { 3D TTE } \\
\text { A (7) }\end{array}$} & \multirow{2}{*}{$\begin{array}{c}\begin{array}{c}\text { Exercise } \\
\text { Testing }\end{array} \\
\text { A (7) }\end{array}$} & \multirow{2}{*}{$\begin{array}{l}\text { CMR } \\
R(2)\end{array}$} & \multirow{2}{*}{$\begin{array}{l}\text { ANG } \\
\text { A (7) }\end{array}$} \\
\hline 86. & - & Determine patient eligibility* & & & & & & \\
\hline
\end{tabular}

3D, 3-dimensional; $A$, appropriate; $A N G$, invasive coronary angiography/ventriculography/aortography; $C M R$, cardiovascular magnetic resonance imaging; $F D A$, U.S. Food and Drug Administration; $M$, may be appropriate; $R$, rarely appropriate; $T E E$, transesophageal echocardiography; TTE, transthoracic echocardiography

${ }^{*}$ Determine patient eligibility. Currently, MitraClip is the only FDA-approved device available

Table 13. Intraprocedural Evaluation During Percutaneous Mitral Valve Repair

\begin{tabular}{|c|c|c|c|c|c|}
\hline \multicolumn{2}{|c|}{ Indication } & \multirow{2}{*}{$\begin{array}{c}\text { TTE } \\
\text { R (1) }\end{array}$} & \multirow{2}{*}{$\begin{array}{c}\begin{array}{c}\text { TEE (With } \\
\text { Possible 3D) }\end{array} \\
\text { A (9) }\end{array}$} & \multirow{2}{*}{$\frac{\text { 3D TTE }}{\text { M (4) }}$} & \multirow{2}{*}{$\begin{array}{c}\begin{array}{c}\text { Angiography/ } \\
\text { Fluoro }\end{array} \\
\text { A (8) }\end{array}$} \\
\hline 88. & - Alignment of the device over the origin of the regurgitant jet and advance to the LV & & & & \\
\hline 90. & - Assess for adequacy in the reduction of the MR & M (4) & A (9) & $M(6)$ & A (7) \\
\hline 91. & - Assess for presence of mitral stenosis & M (5) & $A(9)$ & M (6) & $\mathbf{R}(\mathbf{1})$ \\
\hline
\end{tabular}

3D, 3-dimensional; $A$, appropriate; Fluoro, fluoroscopy; $M$, may be appropriate; $M R$, mitral regurgitation; $R$, rarely appropriate; $T E E$, transesophageal echocardiography; TTE, transthoracic echocardiography

Table 14. Postprocedural Assessment After Percutaneous Mitral Valve Repair (Out of Procedure)

\begin{tabular}{llcccc}
\hline Indication & & TTE & $\begin{array}{c}\text { TEE (With } \\
\text { Possible 3D) }\end{array}$ & $\begin{array}{c}\text { Exercise } \\
\text { Testing }\end{array}$ & CMR \\
\hline 92. & $\begin{array}{l}\text { Reassessment for degree of MR and left ventricular function } \\
\text { (predischarge at } 1,6 \text {, and } 12 \mathrm{~m} \text {, and then annually to } 5 \mathrm{y})\end{array}$ & A (9) & R (3) & M (5) \\
\hline
\end{tabular}

3D, 3-dimensional; $A$, appropriate; $C M R$, cardiovascular magnetic resonance imaging; $M$, may be appropriate; $M R$, mitral regurgitation; $R$, rarely appropriate; TEE, transesophageal echocardiography; TTE, transthoracic echocardiography 


\section{DISCUSSION}

AUC are intended to inform clinicians, patients, and health policy makers about the reasonable use of technologies to help improve patient symptoms and health outcomes. Since 2005, the ACC, along with its professional partners, has worked to provide criteria for both invasive and noninvasive testing and selected treatments, with the intention of further expanding the AUC portfolio. ${ }^{1,2,7,11-14}$

The "2017 Appropriate Use Criteria for Multimodality Imaging in Valvular Heart Disease" is the culmination of the analysis of various modalities used in the evaluation and treatment of patients with VHD. This document signals a shift from documents evaluating a single modality in various disease states to documents evaluating multiple imaging modalities and focusing on evidence and clinical experience within a given category of disease. We believe that this approach better reflects clinical decision making in real-world scenarios and offers the diagnostic choices available to the clinician.

Because a given modality may address diverse disease states, indications previously compiled in a single document may be spread over several AUC documents. The previous VHD-related indications that the current paper supplants are contained in the echocardiography, ${ }^{14}$ radionuclide imaging, ${ }^{13}$ and computed tomography/magnetic resonance imaging ${ }^{11,12}$ AUC documents. Other indications in these documents remain in force until these scenarios are evaluated in subsequent documents.

The tables in this paper are organized to reflect the spectrum of patients with VHD-from patients with no symptoms suspected of having VHD to patients with signs and symptoms ranging from mild to severe. The first 2 tables are for initial evaluation when no prior imaging has been done. As is noted, the diagnostic choices vary between the tables and reflect the options that would be considered in the initial evaluation by most clinicians. If a diagnostic test would seldom or never be considered, it was not included as an option for the rating panel.

In the asymptomatic patient either who is at risk of developing VHD or in whom VHD was clinically suspected, TTE was rated Appropriate for these indications. Three-dimensional (3D) TTE was rated May Be Appropriate for indications 2 and 3. All other modalities (computed tomography, magnetic resonance imaging, and TEE) were rated Rarely Appropriate. These are new indications, so there are no prior ratings in older documents for comparison.

Table 4 evaluates the symptomatic patient. This table adds exercise stress echocardiography, dobutamine stress echocardiography, radionuclide ventriculography, fluorodeoxyglucose-positron emission tomography, and myocardial perfusion imaging/single-photon emission computed tomography/positron emission tomography. In general, echocardiography was the preferred option for initial testing in such patients. The ratings correlate well with those in the prior echocardiography AUC, ${ }^{14}$ with the exception of the evaluation of presyncope, which was rated May Be Appropriate here and Inappropriate ("I" in the old nomenclature) in the prior document. This difference is minor and is attributable to the fact that the symptom of lightheadedness was included with presyncope in the older document, which may have prompted the rating panel to apply a lower rating to echocardiography. All other ratings in this table are either in line with prior rankings or are new scenarios not included in prior documents.

Table 5 evaluates the use of subsequent imaging in scenarios in which prior imaging-presumably using TTE—did not yield a clear diagnosis. The diagnostic options are the same as in Table 4, with the exclusion of TTE. The table is further subdivided into inadequate TTE images, suspected endocarditis, various types of VHD, and valvular mass.

In Table 5, TEE is rated Appropriate and TTE with contrast as May Be Appropriate in evaluating native and prosthetic valves with inadequate images. ${ }^{21,22}$ TEE is also rated Appropriate and fluorodeoxyglucose-positron emission tomography as May Be Appropriate in the diagnosis of endocarditis in patients with a negative TTE. Scenarios 23 to 25 identify the role of low-dose dobutamine stress echocardiography in patients with low-flow, low-gradient severe aortic stenosis (with low ejection fraction as Appropriate and preserved ejection fraction as May Be Appropriate). ${ }^{23-25}$ Exercise stress echocardiography and dobutamine stress echocardiography were rated Rarely Appropriate in patients with severe, symptomatic AS. The common conundrum of evaluating the severity of MR-examined in scenarios 28 to 32-particularly distinguishing moderate from severe MR, elucidating the discrepancy between symptoms and severity, and evaluating an ischemic etiology of MR, demonstrates the role of various modalities in these very specific but very common scenarios. ${ }^{26}$ These indications are new and are not included in prior documents.

Table 6 evaluates sequential or follow-up imaging in various stages of VHD and incorporates the newer VHD classification ${ }^{4}$ where TTE ratings are in line with the prior echocardiography $\mathrm{AUC}^{14}$ and reflect the primacy of TTE at appropriate intervals in following patients with VHD. Time intervals shorten with the severity of VHD, and the role of exercise stress echocardiography—rated May Be Appropriate-in evaluating patients with severe and asymptomatic AS to aid in clinical decision making is highlighted. TTE in patients with moderate or severe AS imaged with a $<1$ - 
year time interval when subjected to increased hemodynamic demands is rated May Be Appropriate and can be considered on a case-by-case basis. The utility of cardiac computed tomography (CCT) or cardiovascular magnetic resonance imaging in evaluating the ascending aorta in patients with a bicuspid aortic valve is defined in indications 49 to 51 .

Table 7 evaluates new or worsening symptoms. In the general scenarios, TTE is rated Appropriate and TEE is rated May Be Appropriate. In the specific endocarditis scenario, both TTE and TEE are rated Appropriate.

Table 8 evaluates postoperative imaging in patients undergoing surgical valve replacement and/or mitral repair. In patients with no symptoms (indications 57 to 61), the interval of follow-up (which is limited to TTE) aligns well with the prior document, with the exception of the evaluation of a mechanical or bioprosthetic valve with TTE in $<3$ years-indication $58 .{ }^{14}$ In the current document, it is rated May Be Appropriate. In the prior AUC, it was rated Inappropriate (old nomenclature). Reasons for this difference are not apparent, but may be related to rating panel composition, which can account for small differences. The authors suggest that there are cases in which follow-up imaging may be done in a shorter time frame, such as small prosthesis size and an elevated transvalvular gradient by Doppler.

Whereas TTE is the modality of choice in the asymptomatic patient, TEE is considered Appropriate, and 3D TTE May Be Appropriate and useful in the evaluation of patients with suspected prosthetic valve dysfunction.

Section 6.3. (Tables 9, 10, 11, 12, 13, 14) evaluates the dynamic field of structural valve interventions. Tables 9, 10, 11 cover preprocedural, intraprocedural, and postprocedural imaging for transcatheter aortic valve replacement (TAVR) for AS. ${ }^{27,28}$ Table 9 catalogues all of the necessary measurements in the preTAVR evaluation. It is worth noting that this table covers the imaging support needed and not whether the procedure should be done. The latter is being evaluated in an AUC document for severe AS, which is currently under development. It is in the AS AUC that CCT and cardiovascular magnetic resonance imaging, as advanced imaging techniques, establish themselves as essential technologies for planning these procedures. Likewise, assessment for concomitant coronary artery disease is accomplished through CCT, myocardial perfusion imaging/single-photon emission computed tomography/positron emission tomography, and angiography.

Intraprocedural evaluation (Table 10) is accomplished with TTE, TEE, angiography, and fluoroscopy. Because TAVR procedures are increasingly being performed with conscious sedation, $\mathrm{TTE}^{29}$ is being increasingly used in lieu of TEE. Both modalities are rated Appropriate.

Postprocedural assessment (Table 11) for valve dysfunction can be accomplished with TTE or TEE rated as Appropriate tests, with the additional use of 3D TTE rated as May Be Appropriate. CCT or cardiovascular magnetic resonance imaging are both rated May Be Appropriate. For assessment of stroke, TTE is rated Appropriate, whereas TEE and CCT are rated May Be Appropriate. Brain imaging with computed tomography or magnetic resonance imaging is rated Appropriate.

For percutaneous mitral valve repair (Table 12, 13, 14), there is only 1 U.S. Food and Drug Administrationapproved device and imaging support, especially in follow-up, hence, the U.S. Food and Drug Administration-directed protocol. ${ }^{30}$ Patient eligibility (including assessment for concomitant coronary artery disease) is assessed with TTE, TEE, 3D TTE, exercise testing of various types, and coronary angiography, all of which are rated Appropriate. If there is concern regarding an intracardiac mass, thrombus, or vegetation, this is assessed with TEE, as Appropriate, whereas TTE is rated as May Be Appropriate, as is 3D TTE.

Intraprocedural assessment is accomplished with TEE as Appropriate and angiography/fluoroscopy as Appropriate for all measures except for the presence of mitral stenosis, which is assessed with TEE as Appropriate. TTE and 3D TTE are also useful for some determinations during the procedure as May Be Appropriate, but TEE offers a more comprehensive examination and is rated Appropriate.

The postprocedure assessment is currently determined by U.S. Food and Drug Administration regulations and involves echocardiography predischarge at 1,6 , and 12 months and annually up to 5 years. TTE is rated Appropriate and 3D TTE is rated May Be Appropriate.

\section{CONCLUSIONS}

This document assesses a wide array of imaging modalities available to the clinician in the evaluation of patients with VHD. Presented here is a broad spectrum of clinical scenarios in such patients. Some of these scenarios replicate those of prior documents, but many are new, specifically, structural valve interventions, which were not in the armamentarium of clinicians when prior, single-modality documents were published. Where comparisons can be made, the ratings are remarkably consistent with prior documents.

We believe the multimodality approach more closely replicates clinical decision making and will be useful. Future documents will not provide single-source 
guidance for appropriateness in all disease states. Echocardiography indications, for example, will be spread across complimentary documents such as multimodality stable ischemic heart disease AUC, multimodality structural heart disease AUC, the current document, and multimodality preoperative evaluation AUC, which is under development.

A few clinical scenarios, describing evaluation of symptoms that could be secondary to valvular or structural heart disease, can be found in both documents (e.g., the evaluation of pre-syncope/syncope in Table 4). Although these scenarios were developed against a background of both valvular and structural heart disease, they were rated separately in the context of other clinical scenarios focused on either valvular or structural heart disease. The writing group and its representatives have placed particular emphasis on this issue during all stages of the development of the AUC document to avoid discordant recommendations for these scenarios.

As with all prior documents, the evaluation is a product of current guidelines, where available, and expert consensus. The modalities are not to be considered in a rank order and may be used relative to individual patient circumstances and risk versus benefit. Accordingly, a study rated May Be Appropriate should not be denied reimbursement in lieu of one rated Appropriate. There will be individual circumstances when a study ranked Rarely Appropriate may be clinically useful if properly documented.

\section{ACC PRESIDENT AND STAFF}

Mary Norine Walsh, MD, FACC, President

Shalom Jacobovitz, Chief Executive Officer

William J. Oetgen, MD, FACC, Executive Vice President, Science, Education, Quality, and Publishing

Joseph M. Allen, MA, Team Leader, Clinical Policy and Pathways

Leah White, MPH, CCRP, Team Leader, Appropriate Use Criteria

María Velásquez, Senior Research Specialist, Appropriate Use Criteria

Amelia Scholtz, PhD, Publications Manager, Science, Education, Quality, and Publishing

\section{RATING PANEL MEMBERS}

Greg J. Dehmer, MD, MACC, MSCAI, FACP, FAHA, Moderator*, John U. Doherty, MD, FACC, FAHA, Writing Group Liaison*, Paul Schoenhagen, MD, FAHA, Writing Group Liaison ${ }^{\S}$, Zahid Amin, MD, FSCAI, FAHA ${ }^{*}$, Thomas M. Bashore, MD, FACC*,
Andrew Boyle, MD*, Dennis A. Calnon, MD, FACC, FASE, MASNC, FSCCT ${ }^{\|}$, Blase Carabello, MD, FACC* ${ }^{*}$, Manuel D. Cerqueira, MD, FACC, MASNC*, John Conte, MD ${ }^{\top}$, Milind Desai, MD, FACC*, Daniel Edmundowicz, MD, FACC*, Victor A. Ferrari, MD, FACC $^{\#}$, Brian Ghoshhajra MD, MBA ${ }^{\S}$, Praveen Mehrotra, MD, FACC* ${ }^{*}$ Saman Nazarian, MD, PHD**, T. Brett Reece, $\mathrm{MD}^{\dagger \dagger}$, Balaji Tamarappoo, MD, PHD*, Wendy S. Tzou, MD, FACC, FHRS ${ }^{\dagger+}$, John B. Wong, MD. 'Society of Thoracic Surgeons Representative.

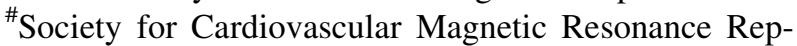
resentative. ${ }^{* *}$ Heart Rhythm Society Representative. ${ }^{\dagger}$ American Association for Thoracic Surgery Representative. ${ }^{\dagger}$ American Heart Association Representative.

\section{APPROPRIATE USE CRITERIA TASK FORCE}

John U. Doherty, MD, FACC, FACP, FAHA, CoChair, Gregory J. Dehmer, MD, MACC, MSCAI, FACP, FAHA, Co-Chair, Steven R. Bailey, MD, FACC, MSCAI, FAHA, Nicole M. Bhave, MD, FACC, Alan S. Brown, MD, FACC ${ }^{\S \S}$, Stacie L. Daugherty, MD, FACC, Larry S. Dean, MD, FACC, MSCAI, Milind Y. Desai, MBBS, FACC, Claire S. Duvernoy, MD, FACC ${ }^{\S \S}$, Linda D. Gillam, MD, FACC, Robert C. Hendel, MD, FACC, FAHA ${ }^{\S \S}$, Christopher M. Kramer, MD, FACC, FAHA $^{\|\| \|}$, Bruce D. Lindsay, MD, FACC ${ }^{\S \S}$, Warren J. Manning, MD, FACC, Praveen Mehrotra, MD, FACC, FASE, Manesh R. Patel, MD, FACC, FSCAI, FAHA ${ }^{\bullet \uparrow}$, Ritu Sachdeva, MBBS, FACC, L. Samuel Wann, MD, MACC $^{\S \S}$, David E. Winchester, MD, FACC, Michael J. Wolk, MD, MACC ${ }^{\S \S}$, Joseph M. Allen, MA. ${ }^{\S \S}$ Former Task Force member; current member during writing effort. ${ }^{\|\|}$Former Task Force co-chair; current co-chair during writing effort. ${ }^{\top \top}$ Former Task Force chair; current chair during writing effort.

\section{References}

1. Patel MR, Spertus JA, Brindis RG, et al. ACCF proposed method for evaluating the appropriateness of cardiovascular imaging. J Am Coll Cardiol. 2005;46:1606-13.

2. Hendel RC, Patel MR, Allen JM, et al. Appropriate use of cardiovascular technology: 2013 ACCF appropriate use criteria methodology update: A report of the American College of Cardiology Foundation Appropriate Use Criteria Task Force. J Am Coll Cardiol. 2013;61:1305-17.

3. Fitch K, Bernstein SJ, Aguilar MD, et al. The RAND/UCLA Appropriateness Method User's Manual. Arlington, VA: RAND; 2001.

4. Nishimura RA, Otto CM, Bonow RO, et al. 2017 AHA/ACC focused update of the 2014 AHA/ACC Guideline for the Management of Patients With Valvular Heart Disease. J Am Coll Cardiol. 2017;70:252-89.

5. Nishimura RA, Otto CM, Bonow RO, et al. 2014 AHA/ACC guideline for the management of patients with valvular heart 
disease: A report of the American College of Cardiology/American Heart Association Task Force on Practice Guidelines. J Am Coll Cardiol. 2014;63:e57-185.

6. Hunt SA, Abraham WT, Chin MH, et al. 2009 focused update incorporated into the ACC/AHA 2005 Guidelines for the Diagnosis and Management of Heart Failure in Adults: A report of the American College of Cardiology Foundation/American Heart Association Task Force on Practice Guidelines. J Am Coll Cardiol. 2009;53:e1-90.

7. Wolk MJ, Bailey SR, Doherty JU, et al. 2013 ACCF/AHA/ASE/ ASNC/HFSA/HRS/SCAI/SCCT/SCMR/STS multimodality appropriate use criteria for the detection and risk assessment of stable ischemic heart disease: A report of the American College of Cardiology Foundation Appropriate Use Criteria Task Force, American Heart Association, American Society of Echocardiography, American Society of Nuclear Cardiology, Heart Failure Society of America, Heart Rhythm Society, Society for Cardiovascular Angiography and Interventions, Society of Cardiovascular Computed Tomography, Society for Cardiovascular Magnetic Resonance, and Society of Thoracic Surgeons. J Am Coll Cardiol. 2014;63:380-406.

8. Fihn SD, Blankenship JC, Alexander KP, et al. 2014 ACC/AHA/ AATS/PCNA/SCAI/STS focused update of the guideline for the diagnosis and management of patients with stable ischemic heart disease: A report of the American College of Cardiology/American Heart Association Task Force on Practice Guidelines, and the American Association for Thoracic Surgery, Preventive Cardiovascular Nurses Association, Society for Cardiovascular Angiography and Interventions, and Society of Thoracic Surgeons. J Am Coll Cardiol. 2014;64:1929-49.

9. Warnes CA, Williams RG, Bashore TM, et al. 2008 ACCF/AHA guidelines for the management of adults with congenital heart disease: A report of the American College of Cardiology Foundation/American Heart Association Task Force on Practice Guidelines (Writing Committee to Develop Guidelines on the Management of Adults With Congenital Heart Disease). J Am Coll Cardiol. 2008;52:e1-121.

10. Hiratzka LF, Bakris GL, Beckman JA, et al. 2010 ACCF/AHA/ AATS/ACR/ASA/SCA/SCAI/SIR/STS/SVM guidelines for the diagnosis and management of patients with thoracic aortic disease: A report of the American College of Cardiology Foundation/ American Heart Association Task Force on Practice Guidelines, American Association for Thoracic Surgery, American College of Radiology, American Stroke Association, Society of Cardiovascular Anesthesiologists, Society for Cardiovascular Angiography and Interventions, Society of Interventional Radiology, Society of Thoracic Surgeons, and Society for Vascular Medicine. J Am Coll Cardiol. 2010;55:e27-129.

11. Hendel RC, Patel MR, Kramer CM, et al. 2006 ACCF/ACR/ SCCT/SCMR/ASNC/NASCI/SCAI/SIR appropriateness criteria for cardiac computed tomography and cardiac magnetic resonance imaging: A report of the American College of Cardiology Foundation Quality Strategic Directions Committee Appropriateness Criteria Working Group, American College of Radiology, Society of Cardiovascular Computed Tomography, Society for Cardiovascular Magnetic Resonance, American Society of Nuclear Cardiology, North American Society for Cardiac Imaging, Society for Cardiovascular Angiography and Interventions, and Society of Interventional Radiology. J Am Coll Cardiol. 2006;48:1475-97.

12. Taylor AJ, Cerqueira M, Hodgson JM, et al. 2010 ACCF/SCCT/ ACR/AHA/ASE/ASNC/NASCI/SCAI/SCMR appropriate use criteria for cardiac computed tomography: A report of the American College of Cardiology Foundation Appropriate Use Criteria Task Force, the Society of Cardiovascular Computed Tomography, the American College of Radiology, the American Heart Association, the American Society of Echocardiography, the American Society of Nuclear Cardiology, the North American Society for Cardiovascular Imaging, the Society for Cardiovascular Angiography and Interventions, and the Society for Cardiovascular Magnetic Resonance. J Am Coll Cardiol. 2010;56:1864-94.

13. Hendel RC, Berman DS, Di Carli MF, et al. 2009 ACCF/ASNC/ ACR/AHA/ASE/SCCT/SCMR/SNM appropriate use criteria for cardiac radionuclide imaging: A report of the American College of Cardiology Foundation Appropriate Use Criteria Task Force, the American Society of Nuclear Cardiology, the American College of Radiology, the American Heart Association, the American Society of Echocardiography, the Society of Cardiovascular Computed Tomography, the Society for Cardiovascular Magnetic Resonance, and the Society of Nuclear Medicine. J Am Coll Cardiol. 2009;53:2201-29.

14. Douglas PS, Garcia MJ, Haines DE, et al. 2011 ACCF/ASE/AHA/ ASNC/HFSA/HRS/SCAI/SCCM/SCCT/SCMR appropriate use criteria for echocardiography: A report of the American College of Cardiology Foundation Appropriate Use Criteria Task Force, American Society of Echocardiography, American Heart Association, American Society of Nuclear Cardiology, Heart Failure Society of America, Heart Rhythm Society, Society for Cardiovascular Angiography and Interventions, Society of Critical Care Medicine, Society of Cardiovascular Computed Tomography, and Society for Cardiovascular Magnetic Resonance. J Am Coll Cardiol. 2011;57:1126-66.

15. Halliburton SS, Abbara S, Chen MY, et al. SCCT guidelines on radiation dose and dose-optimization strategies in cardiovascular CT. J Cardiovasc Comput Tomogr. 2011;5:198-224.

16. Pellikka PA, Nagueh SF, Elhendy AA, et al. American Society of Echocardiography recommendations for performance, interpretation, and application of stress echocardiography. J Am Soc Echocardiogr. 2007;20:1021-41.

17. Hansen CL, Goldstein RA, Akinboboye OO, et al. Myocardial perfusion and function: Single photon emission computed tomography. J Nucl Cardiol. 2007;14:e39-60.

18. Kramer CM, Barkhausen J, Flamm SD, et al. Standardized cardiovascular magnetic resonance imaging (CMR) protocols, Society For Cardiovascular Magnetic Resonance: Board of Trustees Task Force On Standardized Protocols. J Cardiovasc Magn Reson. 2008;10:35.

19. Abbara S, Blanke P, Maroules CD, et al. SCCT guidelines for the performance and acquisition of coronary computed tomographic angiography: A report of the Society of Cardiovascular Computed Tomography Guidelines Committee. J Cardiovasc Comput Tomogr. 2016;10:435-49.

20. Naidu SS, Rao SV, Blankenship J, et al. Clinical expert consensus statement on best practices in the cardiac catheterization laboratory: Society for Cardiovascular Angiography and Interventions. Catheter Cardiovasc Interv. 2012;80:456-64.

21. Ward RP, Mansour IN, Lemieux N, et al. Prospective evaluation of the clinical application of the American College of Cardiology Foundation/American Society of Echocardiography Appropriateness Criteria for Transthoracic Echocardiography. J Am Coll Cardiol Img. 2008;1:663-71.

22. Bai AD, Steinberg M, Showler A, et al. Diagnostic accuracy of transthoracic echocardiography for infective endocarditis findings using transesophageal echocardiography as the reference standard: A meta-analysis. J Am Soc Echocardiogr. 2017;30(639-46):e8.

23. Clavel MA, Burwash IG, Pibarot P. Cardiac imaging for assessing low-gradient severe aortic stenosis. J Am Coll Cardiol Img. 2017;10:185-202.

24. Tribouilloy C, Lévy F, Rusinaru D, et al. Outcome after aortic valve replacement for low-flow/low-gradient aortic stenosis 
without contractile reserve on dobutamine stress echocardiography. J Am Coll Cardiol. 2009;53:1865-73.

25. Levy F, Laurent M, Monin JL, et al. Aortic valve replacement for low-flow/low-gradient aortic stenosis operative risk stratification and long-term outcome: A European multicenter study. J Am Coll Cardiol. 2008;51:1466-72.

26. Uretsky S, Gillam L, Lang R, et al. Discordance between echocardiography and MRI in the assessment of mitral regurgitation severity: A prospective multicenter trial. J Am Coll Cardiol. 2015;65:1078-88.

27. Hahn RT, Little SH, Monaghan MJ, et al. Recommendations for comprehensive intraprocedural echocardiographic imaging during TAVR. J Am Coll Cardiol Img. 2015;8:261-87.
28. Otto CM, Kumbhani DJ, Alexander KP, et al. 2017 ACC expert consensus decision pathway for transcatheter aortic valve replacement in the management of adults with aortic stenosis: A report of the American College of Cardiology Task Force on Clinical Expert Consensus Documents. J Am Coll Cardiol. 2017;69:1313-46.

29. Sengupta PP, Wiley BM, Basnet S, et al. Transthoracic echocardiography guidance for TAVR under monitored anesthesia care. $\mathbf{J}$ Am Coll Cardiol Img. 2015;8:379-80.

30. Sorajja P, Mack M, Vemulapalli S, et al. Initial experience with commercial transcatheter mitral valve repair in the United States. J Am Coll Cardiol. 2016;67:1129-40. 